\title{
Scn2a severe hypomorphic mutation decreases excitatory synaptic input and causes autism-associated behaviors
}

\author{
Hong-Gang Wang, ${ }^{1}$ Charlotte C. Bavley, ${ }^{2,3}$ Anfei Li, ${ }^{2}$ Rebecca M. Jones, ${ }^{4,5,6}$ Jonathan Hackett, ${ }^{3}$ \\ Yared Bayleyen, ${ }^{1}$ Francis S. Lee, ${ }^{2,5,6}$ Anjali M. Rajadhyaksha, ${ }^{2,3,5}$ and Geoffrey S. Pittt ${ }^{1,5}$ \\ ${ }^{1}$ Cardiovascular Research Institute, ${ }^{2}$ Feil Family Brain and Mind Research Institute, and ${ }^{3}$ Pediatric Neurology, Department \\ of Pediatrics, Weill Cornell Medicine, New York, New York, USA. ${ }^{4}$ Weill Cornell Medicine, Center for Autism and the \\ Developing Brain, White Plains, New York, USA. ${ }^{5}$ Weill Cornell Autism Research Program and ${ }^{6}$ Sackler Institute for \\ Developmental Psychobiology, Department of Psychiatry, Weill Cornell Medicine, New York, New York, USA.
}

SCN2A, encoding the neuronal voltage-gated $\mathrm{Na}^{+}$channel $\mathrm{Na}_{v} 1.2$, is one of the most commonly affected loci linked to autism spectrum disorders (ASDs). Most ASD-associated mutations in SCN2A are loss-of-function mutations, but studies examining how such mutations affect neuronal function and whether Scn2a mutant mice display ASD endophenotypes have been inconsistent. We generated a protein truncation variant Scn2a mouse model (Scn2 $a^{\Delta 1898 /+}$ ) by CRISPR that eliminates the $\mathrm{Na}_{\mathrm{v}} \mathrm{1.2}$ channel's distal intracellular C-terminal domain, and we analyzed the molecular and cellular consequences of this variant in a heterologous expression system, in neuronal culture, in brain slices, and in vivo. We also analyzed multiple behaviors in WT and Scn2 $a^{\Delta 1898 /+}$ mice and correlated behaviors with clinical data obtained in human subjects with SCN2A variants. Expression of the $\mathrm{Na}_{v} 1.2$ mutant in a heterologous expression system revealed decreased $\mathrm{Na}_{\mathrm{v}} 1.2$ channel function, and cultured pyramidal neurons isolated from Scn2 $a^{\Delta 1898 /+}$ forebrain showed correspondingly reduced voltage-gated $\mathrm{Na}^{+}$channel currents without compensation from other CNS voltage-gated $\mathrm{Na}^{+}$channels. $\mathrm{Na}^{+}$currents in inhibitory neurons were unaffected. Consistent with loss of voltage-gated $\mathrm{Na}^{+}$channel currents, $\operatorname{Scn} 2 a^{\Lambda 1898 /+}$ pyramidal neurons displayed reduced excitability in forebrain neuronal culture and reduced excitatory synaptic input onto the pyramidal neurons in brain slices. Scn2 $a^{\Lambda 1898 /+}$ mice displayed several behavioral abnormalities, including abnormal social interactions that reflect behavior observed in humans with ASD and with harboring loss-of-function SCN2A variants. This model and its cellular electrophysiological characterizations provide a framework for tracing how a SCN2A loss-of-function variant leads to cellular defects that result in ASD-associated behaviors.

Conflict of interest: The authors have declared that no conflict of interest exists.

Copyright: (c) 2021, Wang et al. This is an open access article published under the terms of the Creative Commons Attribution 4.0 International License.

Submitted: April 20, 2021

Accepted: June 17, 2021

Published: August 9, 2021

Reference information: /CI Insight. 2021;6(15):e150698.

https://doi.org/10.1172/jici. insight.150698.

\section{Introduction}

Within the CNS, voltage-gated $\mathrm{Na}^{+}\left(\mathrm{Na}_{\mathrm{v}}\right)$ channels such as the $S C N 2 A$-encoded $\mathrm{Na}_{\mathrm{v}} 1.2$ initiate action potentials (APs) and are, thus, fundamental to defining neuronal excitability. In addition to $\mathrm{Na}_{\mathrm{v}} 1.2$, which is found in excitatory neurons and a small set of inhibitory interneurons (1), the major brain $\mathrm{Na}_{\mathrm{v}}$ channels are $S C N 1 A$-encoded $\mathrm{Na}_{\mathrm{v}} 1.1$ (expressed mainly in inhibitory neurons), $S C N 3 A$-encoded $\mathrm{Na}_{\mathrm{v}} 1.3$ (expressed in embryonic neurons), and $S C N 8 A$-encoded $\mathrm{Na}_{\mathrm{v}} 1.6$ (found in excitatory and inhibitory neurons). Most mature excitatory CNS neurons express $\mathrm{Na}_{\mathrm{v}} 1.2$ and $\mathrm{Na}_{\mathrm{v}} 1.6$, and these $\mathrm{Na}_{\mathrm{v}}$ channels confer distinct features that tweak electrical activity and contribute to the defining features of AP initiation and conduction in different types of neurons. During early brain development, $\mathrm{Na}_{\mathrm{v}} 1.2$ is the dominant $\mathrm{Na}^{+}$channel expressed in excitatory neurons, where it predominantly localizes to the axon initial segment $(2,3)$. Because of this preferential expression of $\mathrm{Na}_{\mathrm{v}} 1.2$ during the vulnerable developmental period when most autism spectrum disorder-associated (ASD-associated) mutations exert their influence (4), $\mathrm{Na}_{\mathrm{v}} 1.2$ is well positioned to exert a potent effect on AP initiation and conduction, thereby influencing neuronal excitability and activity-dependent development in the maturing brain.

Next-generation sequencing studies of de novo mutations in subjects with ASD have consistently identified $S C N 2 A$ as one of the most commonly associated loci (5-7), and $S C N 2 A$ is also among the top loci identified with postzygotic mutations associated with ASD (8). Variants in $S C N 2 A$ have also been linked to several other neurological disorders, including epilepsy and intellectual disability (9). Analyses in heterologous 
expression systems of several disease-associated $S C N 2 A$ variants found that ASD-associated mutations generally cause channel loss-of-function effects (often because of protein truncation variants), while epilepsyassociated mutations reveal various biophysical gain-of-function effects (increased $\mathrm{Na}^{+}$influx) (10).

Recent examinations of $\operatorname{Scn} 2 a$ heterozygous KO $\left(\operatorname{Scn} 2 a^{+/-}\right)$mice showed that, in addition to the critical role in the axonal excitability in early development, $\mathrm{Na}_{\mathrm{v}} 1.2$ is crucial to AP backpropagation, dendritic excitability, synaptic transmission, and synaptic plasticity in mature pyramidal neurons $(11,12)$. These $\operatorname{Scn} 2 a^{+/-}$ mice revealed a decrease in learning and memory (13), but other behavioral consequences, especially those associated with autistic-like behaviors, were highly variable and often inconsistent $(11,12,14,15)$. Therefore, the specific contribution of $\mathrm{Na}_{\mathrm{v}} 1.2$ dysfunction to ASD endophenotypes has not been determined.

A perturbation of the delicate balance between neuronal excitation and inhibition (E/I balance) has been implicated in a range of neurodevelopmental disorders (4), and a leading hypothesis is that ASD results from an $\mathrm{E} / \mathrm{I}$ imbalance in developing circuits during the critical neonatal period $(16,17)$. By exploiting mice with a $\mathrm{Na}_{\mathrm{v}} 1.2$ protein truncation variant $\left(\operatorname{Scn} 2 a^{\Delta 1898 /+}\right)$ leading to severe reduction in channel function, we investigated the consequences on neuronal cellular properties and synaptic transmission to examine effects on $\mathrm{E} / \mathrm{I}$ balance and ASD-associated behaviors. We found that severe reduction of $\mathrm{Na}_{\mathrm{v}} 1.2$ function reduced neuronal excitability in cultured forebrain pyramidal neurons isolated from Scn $2 a^{\Delta 1898 /+}$ forebrains, and it decreased excitatory synaptic input to pyramidal neurons in the medial prefrontal cortex (mPFC) and basolateral amygdala (BLA) in acute brain slice from adult $\operatorname{Scn} 2 a^{\Delta 1898 /+}$ mice. Scn $2 a^{\Delta 1898 /+}$ mice displayed several behavioral abnormalities, including enhanced sociability and lack of typical social habituation, consistent with behavior in humans with loss-of-function variants in SCN2A. Together, this model and the accompanying cellular electrophysiological characterizations provide a framework for tracing a $S C N 2 A$ loss-of-function variant to cellular and synaptic defects and the resulting altered $\mathrm{E} / \mathrm{I}$ balance that is associated with ASD-associated behaviors.

\section{Results}

Scn2a severe hypomorph mouse model. Like all other $\mathrm{Na}_{\mathrm{v}}$ channel $\alpha$ subunits, the $S C N 2 A$-encoded $\mathrm{Na}_{\mathrm{v}} 1.2$ has pseudotetrameric repeats of 6 transmembrane segments (Figure 1A) joined by intracellular loops and flanked by cytoplasmic N- and C-termini. The SCN2A transcript contains 27 exons, the last of which is the largest and encodes approximately 400 amino acids that include the fourth tetrameric repeat and the C-terminus. In a compendium accompanying a recent study identifying risk genes with autism and developmental disability biases, 7 of 27 SCN2A mutations were within this exon (consistent with the length of polypeptide as a fraction of the overall length of the channel), 5 of which induced a frameshift and protein truncation (7). Overall, 8 of 27 SCN2A mutations in that compendium had a frameshift, so frameshifts may be overrepresented in this final exon. While generating a single-point mutation mouse knock-in model of an $S C N 2 A$ disease mutation using CRISPR/Cas9 (to be reported separately), we also obtained an indel that produced a frameshift after T1898 in the $\mathrm{Na}_{\mathrm{v}} 1.2$ C-terminus and a subsequent stop codon following 26 potentially novel amino acids (p.T1898NfsX27), as shown in Figure 1A and Supplemental Figure 1 (supplemental material available online with this article; https://doi. org/10.1172/jci.insight.150698DS1). Truncation of $\mathrm{Na}_{\mathrm{v}} 1.2$ at $\mathrm{T} 1898$ eliminates the binding site for the channel auxiliary subunit calmodulin (Figure $1 \mathrm{~A}$ ), which regulates the persistent $\mathrm{Na}^{+}$current $(18,19)$. Because the indel fit a pattern (protein truncation variant in the final exon) common to multiple ASD-associated mutations in $S C N 2 A$, we chose to analyze the consequences of this allele $\left(\operatorname{Scn} 2 a^{\Delta 1898}\right)$ further.

Heterozygous $\operatorname{Scn} 2 a^{\Delta 1898 /+}$ mice were viable and fertile, but we never obtained homozygous $\operatorname{Scn} 2 a^{\Delta 1898 / \Delta 1898}$ mice at weaning from heterozygous crosses $\left(\operatorname{Scn} 2 a^{\Delta 1898 /+}, n=24 ; \mathrm{WT}, n=13 ; \operatorname{Scn} 2 a^{\Delta 1898 / \Delta 1898}, n=0 ; \chi^{2}=12.4, P\right.$ $<0.01$ ). Since $\operatorname{Scn} 2 a^{-1-}$ display perinatal mortality due to hypoxia from absent respirations (20), we suspect that the $\operatorname{Scn} 2 a^{\Delta 1898}$ is a severe hypomorphic allele. The approximately 2:1 ratio of WT to $\operatorname{Scn} 2 a^{\Delta 1898 /+}$ heterozygotes suggests that Scn2a haploinsufficiency does not affect survival, as previously observed (20).

To determine the consequences to $\mathrm{Na}_{\mathrm{v}} 1.2 \mathrm{Na}^{+}$currents, we expressed a frameshifted human $\mathrm{Na}_{\mathrm{v}} 1.2$ channel $\left(\mathrm{Na}_{\mathrm{v}} 1.2^{\Delta 1897}\right.$, equivalent to $\mathrm{Na}_{\mathrm{v}} 1.2^{\Delta 1898}$ in mice) in HEK293 cells and recorded $\mathrm{Na}^{+}$currents by whole-cell voltage clamp. Compared with cells expressing $\mathrm{Na}_{\mathrm{v}} 1.2^{\mathrm{WT}}$ channels, cells with $\mathrm{Na}_{\mathrm{v}} 1.2^{\Delta 1897}$ channels showed markedly decreased $\mathrm{Na}^{+}$current density (Figure 1, B and C). We also measured currents from a human $\mathrm{Na}_{\mathrm{v}} 1.2$ in which we inserted a stop codon after $\mathrm{T} 1897\left(\mathrm{Na}_{\mathrm{v}} 1.2^{1897-\mathrm{STOP}}\right)$, thereby eliminating the alternative 26 amino acids generated by the frameshift, and we observed a similar reduction in current density (Figure 1C). In addition to reducing current density, we found that both the frameshift and the truncation decreased channel availability, as indicated by the leftward shift of the channel steady-state inactivation curves (Figure 1D). The voltage 
A

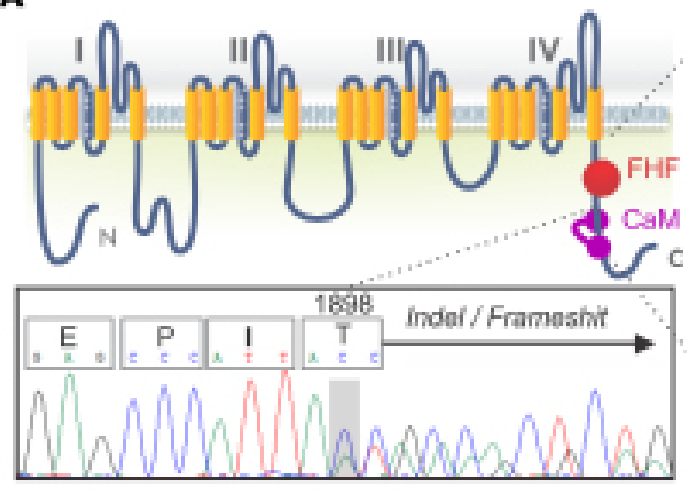

B

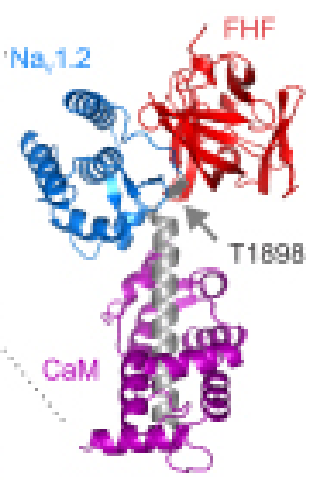

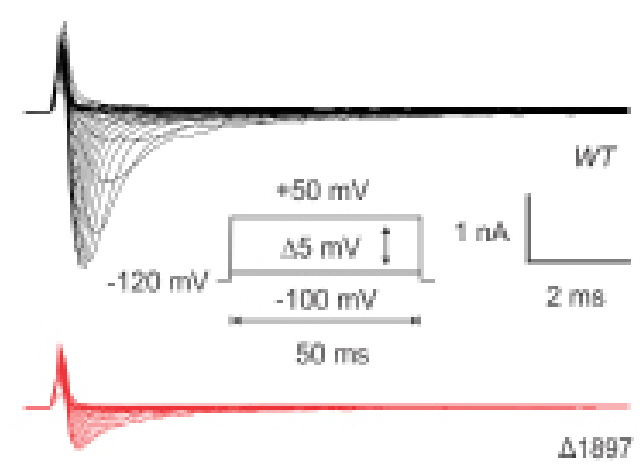

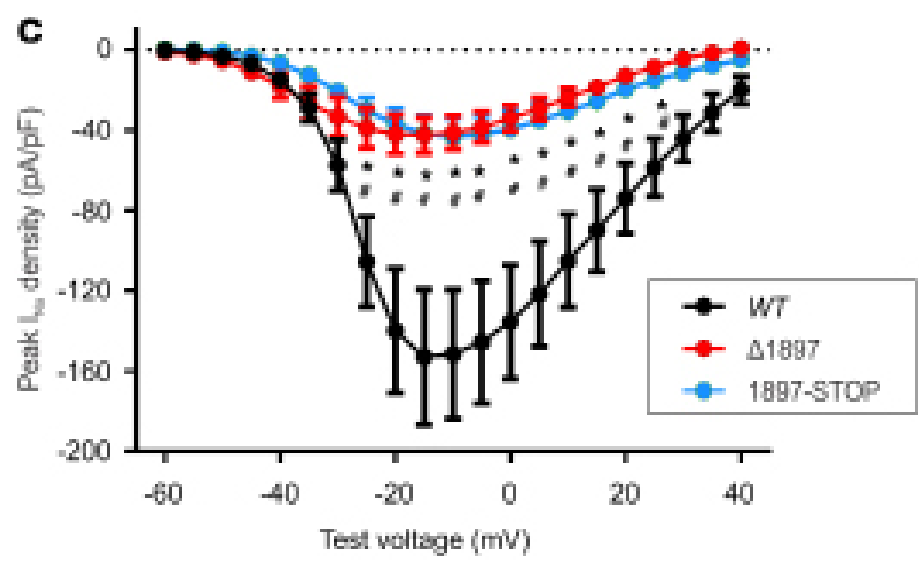

E

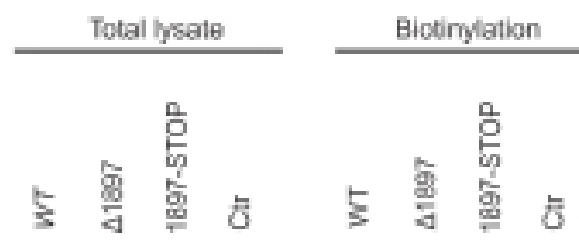

$250 \mathrm{kD}$

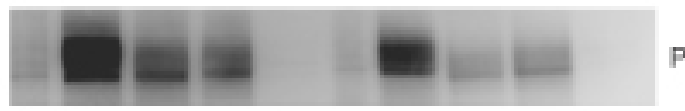

$100 \mathrm{ko}$

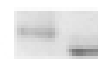

$37 \mathrm{kD}$

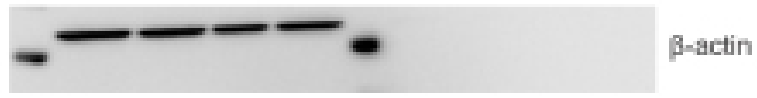

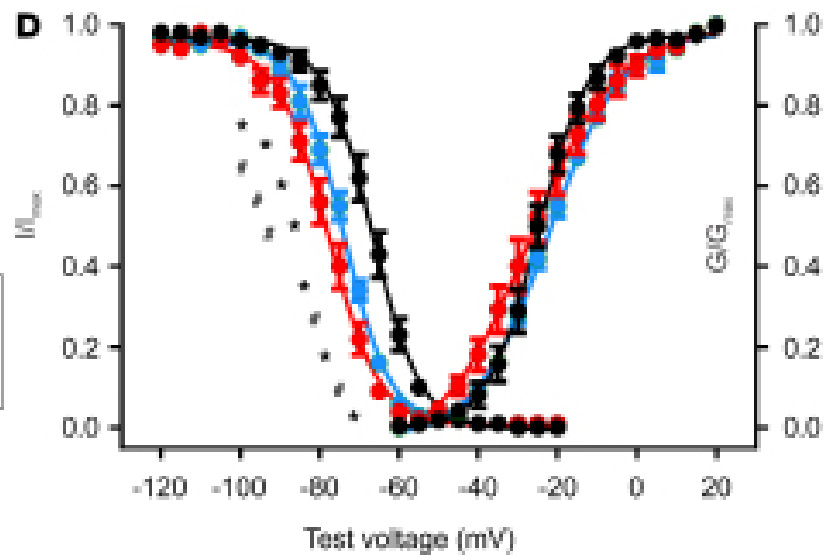

F

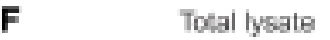

Biatinylation

PanNa

TIR

$\beta$-actin

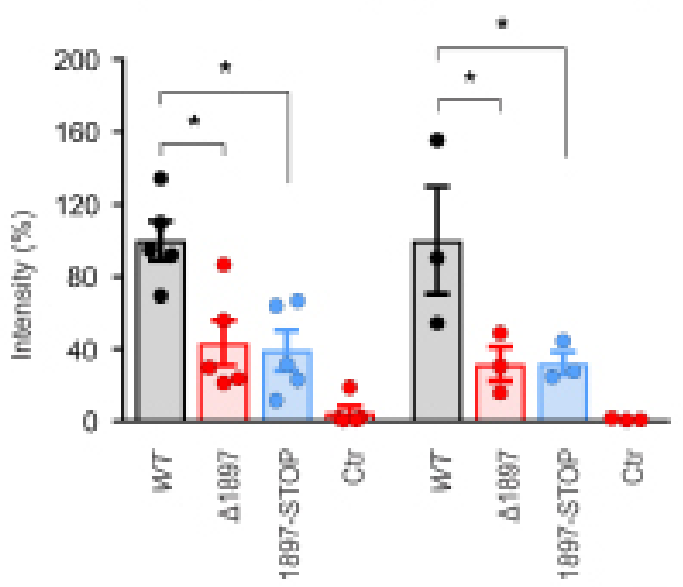

Figure 1. $\mathrm{Na}_{\mathrm{v}} \mathbf{1 . 2}^{\Delta 1897}$ channels display reduced peak $\mathrm{Na}^{+}$current density in transfected cells. (A) Schematic of the $\mathrm{Na}_{\mathrm{v}} 1.2$ pore-forming $\alpha$ subunit. The bottom inset showing genomic DNA sequencing, which demonstrates the T1898N frameshift in one of the alleles in Scn2 $a^{\Delta 1898 /+}$ mice. The right inset shows the location of T1898 on the crystal structure (Protein Data Bank entry: 4JPZ) of the ternary complex of the $\mathrm{Na}_{\mathrm{v}} 1.2$ C-terminal domain (CTD, blue; truncated helix shown in gray), FGF13 (FHF, red), and calmodulin (purple). The arrow indicates the location of T1898. (B) Exemplar current traces for $\mathrm{Na}_{\mathrm{v}} 1.2^{\mathrm{WT}}$ and the frameshifted/truncated $\mathrm{Na}_{\mathrm{v}} 1.2^{\Delta 1897}$ channel (p. T1897NsfX27, equivalent to T1898 in mice) expressed in HEK293 cells. (C) Peak current density-voltage relationships for $\mathrm{Na}_{\mathrm{v}} 1.2^{\mathrm{WT}}(n=11), \mathrm{Na}_{\mathrm{v}} 1.2^{\Delta 1897}(\Delta 1897, n=11)$, and a $\mathrm{Na}_{\mathrm{v}} 1.2$ with a stop codon inserted at T1897 (1897-STOP, $\left.n=12\right)$. Asterisks represent 2-way ANOVA followed by Dunnett's multiple-comparison test. Peak $I_{\text {Na }}$ density $\times$ mutation, $F_{(40,620)}=9.732, P<0.0001$. (D) Steady-state inactivation $\left(I / I_{\max }\right)$ (WT, $n=15 ; \Delta 1897, n=11 ; 1897-S T O P, n=12$ ) and activation $\left(G / G_{\text {max }}\right)$ relationships for the 3 channels. Asterisks represent 2-way ANOVA followed by Dunnett's multiple-comparison test. $1 / I_{\max } \times$ mutation, $F_{(40,700)}=12.34, P<0.0001$. (E) Exemplar immunoblot of whole cell lysates or the biotinylated surface fraction from HEK293 cells expressing the 3 channels. Transferrin receptor (TfR) and actin represent a membrane and cytoplasmic marker, respectively, that demonstrate successful separation of the biotinylated membrane fraction. Molecular weight markers are shown on the left. See complete unedited blots in the supplemental material. (F) Quantification of intensities (relative to WT) from immunoblots (total lysate, $n=5$; biotinylation, $n=3$ ). Asterisks represent 1-way ANOVA followed by Dunnett's multiple-comparison test. Total lysate, $\mathrm{F}_{(3.15)}=15.4, P<0.0001 ; \mathrm{Na}_{v} 1.2^{\mathrm{WT}}$ versus $\mathrm{Na}_{v} 1.2^{\Delta 1897}, P=0.0029 ; \mathrm{Na}_{v} 1.2^{\mathrm{WT}}$ versus 1897-STOP, $P=0.0016$. Biotinylation, $\mathrm{F}_{(3,8)}=6.963, P=0.01 ; \mathrm{Na}_{\mathrm{v}} 1.2^{\mathrm{WT}}$ versus $\Delta 1897, P=0.04 ; \mathrm{Na}_{\mathrm{v}} 1.2^{\mathrm{WT}}$ versus $1897-\mathrm{STOP}, P=0.04$. 
at half-maximal availability $\left(\mathrm{V}_{1 / 2}\right)$ for steady-state inactivation was $-77.9 \mathrm{mV}$ and $-74.0 \mathrm{mV}$ for $\mathrm{Na}_{\mathrm{v}} 1.2^{\Delta 1897}$ and $\mathrm{Na}_{\mathrm{v}} 1.2^{1897-\text { STOP }}$, respectively - a significant hyperpolarizing shift from the $-67.7 \mathrm{mV}$ for the WT channel.

To examine whether the reduced $\mathrm{Na}^{+}$current resulted from less $\mathrm{Na}_{\mathrm{v}} 1.2^{\Delta 1897}$ or $\mathrm{Na}_{\mathrm{v}} 1.2^{1897-\text { STOP }}$ protein inserted into the plasma membrane, we performed surface biotinylation, streptavidin pull down, and quantification of surface $\mathrm{Na}_{\mathrm{v}} 1.2$ by immunoblot. Figure $1, \mathrm{E}$ and $\mathrm{F}$, shows that, compared with $\mathrm{Na}_{\mathrm{v}} 1.2^{\mathrm{WT}}$, total $\mathrm{Na}_{\mathrm{v}} 1.2^{\Delta 1897}$ or $\mathrm{Na}_{\mathrm{v}} 1.2^{1897-\mathrm{STOP}}$ protein was approximately $40 \%$ of $\mathrm{Na}_{\mathrm{v}} 1.2^{\mathrm{WT}}$ and that the amount of $\mathrm{Na}_{\mathrm{v}} 1.2^{\Delta 1897}$ or $\mathrm{Na}_{\mathrm{v}} 1.2^{1897-\mathrm{STOP}}$ inserted into the plasma membrane was similarly reduced to approximately $32 \%$ of $\mathrm{Na}_{\mathrm{v}} 1.2^{\mathrm{WT}}$. These data suggest that the frameshift/truncation led to decreased protein synthesis or increased degradation, but did not exert significant effects on trafficking to the plasma membrane. Since $\mathrm{Na}_{\mathrm{v}} 1.2^{1897}$ and $\mathrm{Na}_{\mathrm{v}} 1.2^{1897-\text { STOP }}$ displayed nearly identical biophysical effects and showed similar degrees of protein instability, we conclude that the additional 26 amino acids generated by the frameshift do not overtly influence $\mathrm{Na}_{\mathrm{v}} 1.2$ channel function. Thus, $\mathrm{Na}_{\mathrm{v}} 1.2^{\Delta 1897}$ behaved as a mutant channel with severely reduced function. These heterologous system data suggest that $\operatorname{Scn} 2 a^{\Delta 1898 /+}$ mice represented an excellent platform to investigate loss-offunction Scn2a-associated ASD in an animal model.

To test whether the mutation also led to reduced $\mathrm{Na}_{\mathrm{v}} 1.2$ protein in vivo as observed in HEK293 cells, we analyzed the amount of $\mathrm{Na}_{\mathrm{v}} 1.2$ protein in lysates from cortex isolated from $S c n 2 a^{\Delta 1898 /+}$ mice and their WT littermates. We generated lysates from $\mathrm{P} 6$ neonates, a stage when $\mathrm{Na}_{\mathrm{v}} 1.2$ is the dominant $\mathrm{Na}_{\mathrm{v}}$ channel in excitable cells before $\mathrm{Na}_{\mathrm{v}} 1.6$ replaces most $\mathrm{Na}_{\mathrm{v}} 1.2$ at the axon initial segment, and separately from adult ( $\sim 5$-month-old) animals. In both P6 and adult mice, we observed less $\mathrm{Na}_{\mathrm{v}} 1.2$ protein in $S c n 2 a^{\Delta 1898 /+}$ mice (reduced by $\sim 60 \%$ ), as detected by 2 different $\mathrm{Na}_{\mathrm{v}} 1.2$-specific antibodies targeting distinct epitopes in the channel (Figure 2, $\mathrm{A}$ and $\mathrm{B}$, and Supplemental Figure 3). Using an antibody that recognizes all $\mathrm{Na}_{\mathrm{v}}$ channels, we did not observe a statistically significant reduction in total $\mathrm{Na}^{+}$channel protein in cortex lysates from P6 neonatal and adult Scn2a $a^{\Delta 1898 /+}$ mice compared with their respective WT littermate controls (Figure 2, A and B, and Supplemental Figure 3). This is likely because $\mathrm{Na}_{\mathrm{v}} 1.2$ is just one of the CNS Na+ channels, and the loss of $\mathrm{Na}_{\mathrm{v}} 1.2$ from 1 Scn2a allele is insufficient to detect a significant reduction in the total $\mathrm{Na}^{+}$channel protein pool.

Truncated proteins are often subjected to rapid degradation. To examine if $\mathrm{Na}_{\mathrm{v}} 1.2^{\Delta 1898}$ channels were subject to degradation, we stained brain slices from newborn WT and Scn2a $a^{\Delta 1898 / \Delta 1898}$ mice (which show perinatal lethality) for $\mathrm{Na}_{\mathrm{v}} 1.2$. $\mathrm{Na}_{\mathrm{v}} 1.2$ was abundantly present in the axonal initial segment (AIS) of WT mice, which was labeled with AIS-specific marker ankyrin G, in the layer 2/3 neocortex from WT mice, but was almost completely absent in the cortical tissue from $\operatorname{Scn} 2 a^{\Delta 1898 / \Delta 1898}$ mice (Figure 2C). These data suggest that $\operatorname{Scn} 2 a^{\Delta 1898}$ encodes an unstable protein and functions as a severe hypomorphic allele.

Since total $\mathrm{Na}^{+}$channel protein in brains from P6 and adult mice was not statistically different between genotypes, we ascertained whether the observed reduction in $\mathrm{Na}_{\mathrm{v}} 1.2$ protein led to a compensatory upregulation of other $\mathrm{Na}^{+}$channel isoforms in the CNS. We performed quantitative PCR (qPCR) on mRNA isolated from the cortex of P3-P6 and adult mice and quantified the relative levels of transcripts for other $\mathrm{Na}^{+}$channel isoforms. We did not observe genotype-specific differences between $\operatorname{Scn} 2 a^{\Delta 1898 /+}$ and WT mice in the transcript levels for Scn1a, Scn2a, Scn3a, or Scn8a (Figure 2, D and E). The fact that there were no genotype-specific differences for $S c n 2 a$ transcripts, specifically, suggests that the reduced $\mathrm{Na}_{\mathrm{v}} 1.2$ protein in $\operatorname{Scn} 2 a^{\Delta 1898 /+}$ mice derives from $\mathrm{Na}_{\mathrm{v}} 1.2^{\Delta 1898}$ protein instability and degradation.

Neuronal cellular consequences of a Scn2a severe hypomorphic allele. Having established the biophysical and biochemical consequences of the severe hypomorphic $S c n 2 a^{\Delta 1898}$ allele, we queried the resulting cellular electrophysiological consequences. To best avoid the voltage clamp challenges of $\mathrm{Na}^{+}$currents in brain slice recordings, we characterized the effect of $S c n 2 a^{\Delta 1898 /+}$ on neuronal cellular properties in young neuronal cultures, when neurons have fewer branches and $\mathrm{Na}_{\mathrm{v}} 1.2$ is the dominantly expressed $\mathrm{Na}^{+}$channel. We isolated forebrain neurons from $\mathrm{P} 1-\mathrm{P} 3$ pups, cultured them for 5-7 days, and recorded total $\mathrm{Na}_{\mathrm{v}}$ currents by whole-cell voltage clamp from pyramidal-shaped (excitatory) neurons (Supplemental Figure 2A). Peak current density was markedly reduced in neurons from Scn2a $a^{\Delta 1898 /+}$ mice compared with their WT littermate controls. The I-V relationships shown in Figure 3A revealed a $\sim 38 \%$ reduction in $\mathrm{Na}^{+}$channel current density in $\operatorname{Scn} 2 a^{\Delta 1898 /+}$ neurons. If we assume, based on the results in Figure 2, that this reduction represents the almost complete loss of 1 Scn $2 a$ allele, we calculate that $\mathrm{Na}_{\mathrm{v}} 1.2$ contributes $\sim 75 \%$ of the total $\mathrm{Na}_{\mathrm{v}}$ channel current in these young cortical pyramidal neurons. Because $\mathrm{Na}_{\mathrm{v}} 1.2$ has also been found in small set of inhibitory interneurons (1), we also analyzed the I-V relationships of $\mathrm{Na}^{+}$currents in nonpyramidal shape neurons (Supplemental Figure 2B). As shown in Figure 3B, there was no difference in current density in $\operatorname{Scn} 2 a^{\Delta 1898 /+}$ versus WT neurons. This is consistent with the reported results (21) showing reduced $\mathrm{Na}_{\mathrm{v}} 1.2$ 
A

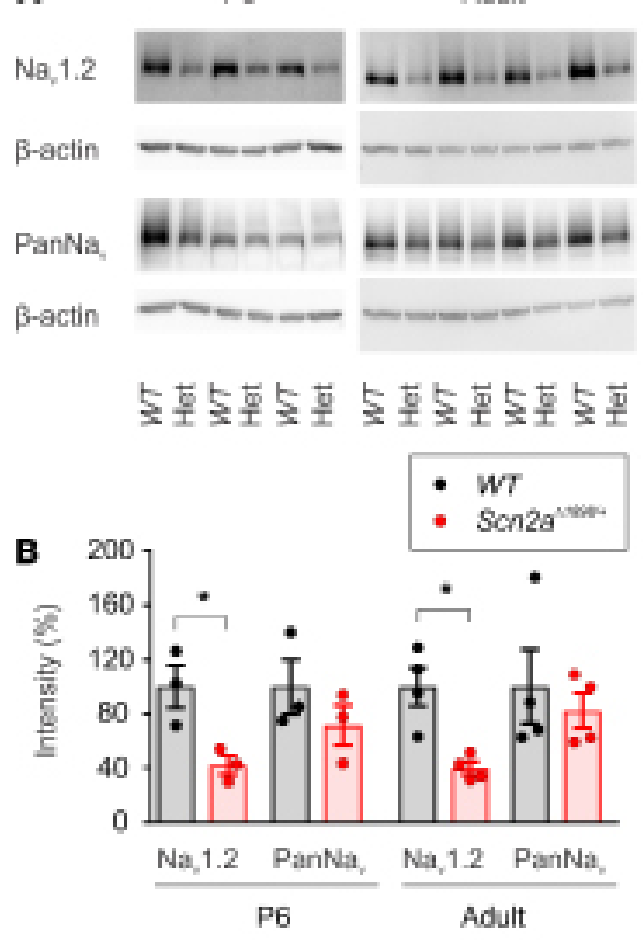

- WT

- $\operatorname{Sen} 2 a^{a^{n}}$
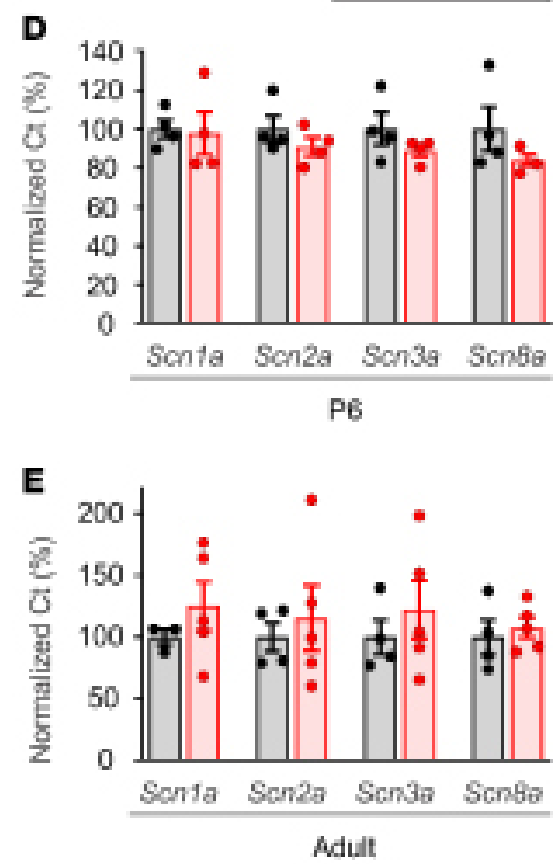

C
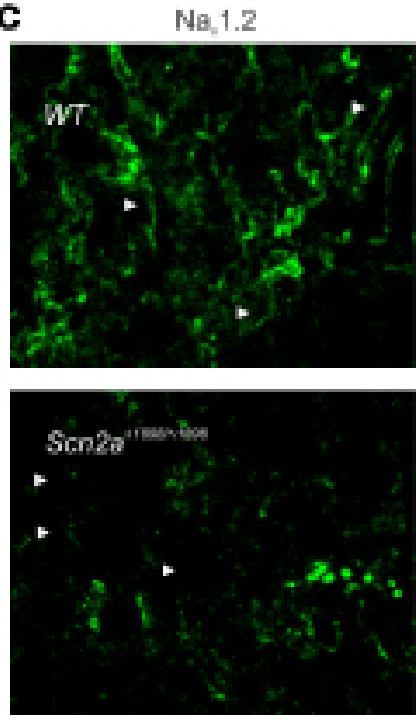
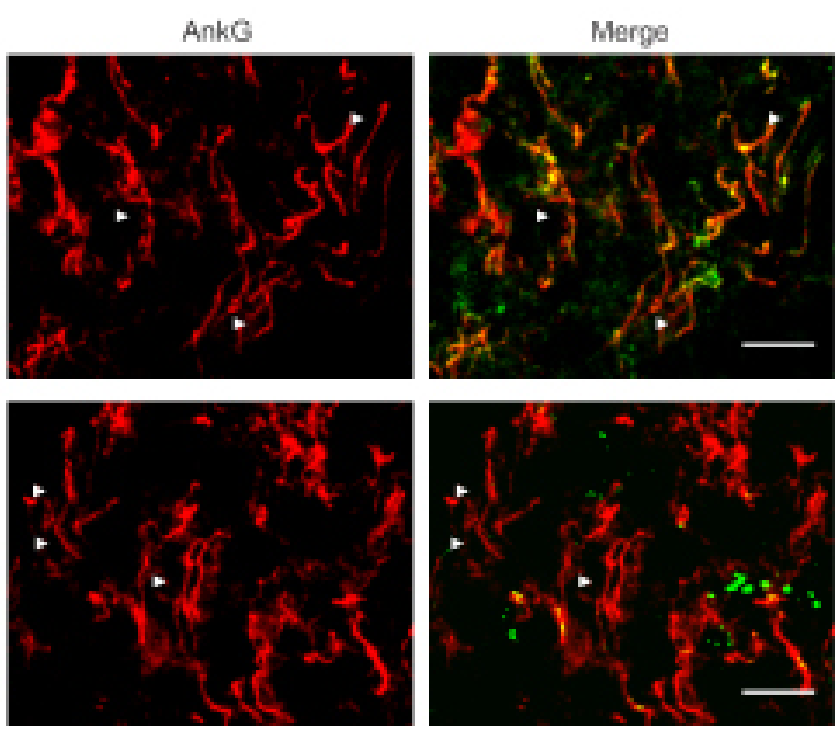

Figure 2. Cortices from Scn2 $a^{41898 /+}$ mice have less total and $\mathrm{Na}_{v} 1.2 \mathrm{Na}_{v}$ channels. (A) Immunoblots for $\mathrm{Na}_{\mathrm{v}} 1.2$ (anti- $\mathrm{Na}_{\mathrm{v}} 1.2$, recognizes amino acids 1882-2005) or total voltage-gated $\mathrm{Na}^{+}$channel $\left(\mathrm{PanNa}_{\mathrm{v}}\right)$ in brain cortex lysates from $\mathrm{P6}(n=3)$ or adult ( 5 month, $n=4$ ) WT or Scn2 $a^{\Delta 1898 /+}$ (Het) mice. Molecular weights are shown on the left. See complete unedited blots in the supplemental material. (B) $\beta$-Actin serves as a loading control and for normalization in $\mathbf{B}$, which shows the quantification of $\mathrm{Na}_{\mathrm{v}} 1.2$ and total $\mathrm{Na}^{+}$channels as in $\mathbf{A}$, normalized to WT. Asterisks represent unpaired $t$ test, $\mathrm{t}_{(4)}=3.348, P=0.03$ for P6; $\mathrm{t}_{(6)}=4.07, P=0.007$ for adult. (C) IHC of layer $2 / 3$ in cortex from P0.5 mice stained with anti-Na 1.2 and anti-ankyrin $\mathrm{G}$ (AnkG) antibodies. The arrows indicate axonal $\mathrm{Na}_{\mathrm{v}} 1.2$ or AnkG. Scale bar: $10 \mu \mathrm{m}$. (D and E) Relative (normalized to GAPDH) CNS Na+ channel transcripts quantified by qPCR in P3-P6 $(n=4)$ and adult ( 5 month; WT, $\left.n=4 ; \operatorname{Scn} 2 a^{\Delta 1898 /+}, n=5\right)$ cortex, respectively.

currents in excitatory, but not inhibitory, neurons. Together, these data further support our interpretation that $\operatorname{Sin} 2 a^{\Delta L 898 /+}$ mice represent a loss-of-function model.

As $\operatorname{Scn} 2 a$ is almost exclusively expressed in excitatory neurons, and since $\mathrm{Na}^{+}$channels drive APs, we characterized APs elicited in the cultured forebrain pyramidal neurons in which we identified the reduction in total $\mathrm{Na}^{+}$currents for $\operatorname{Sin} 2 a^{\Delta 1898 /+}$ mice. We first measured the stimulus threshold at which APs were elicited 
A
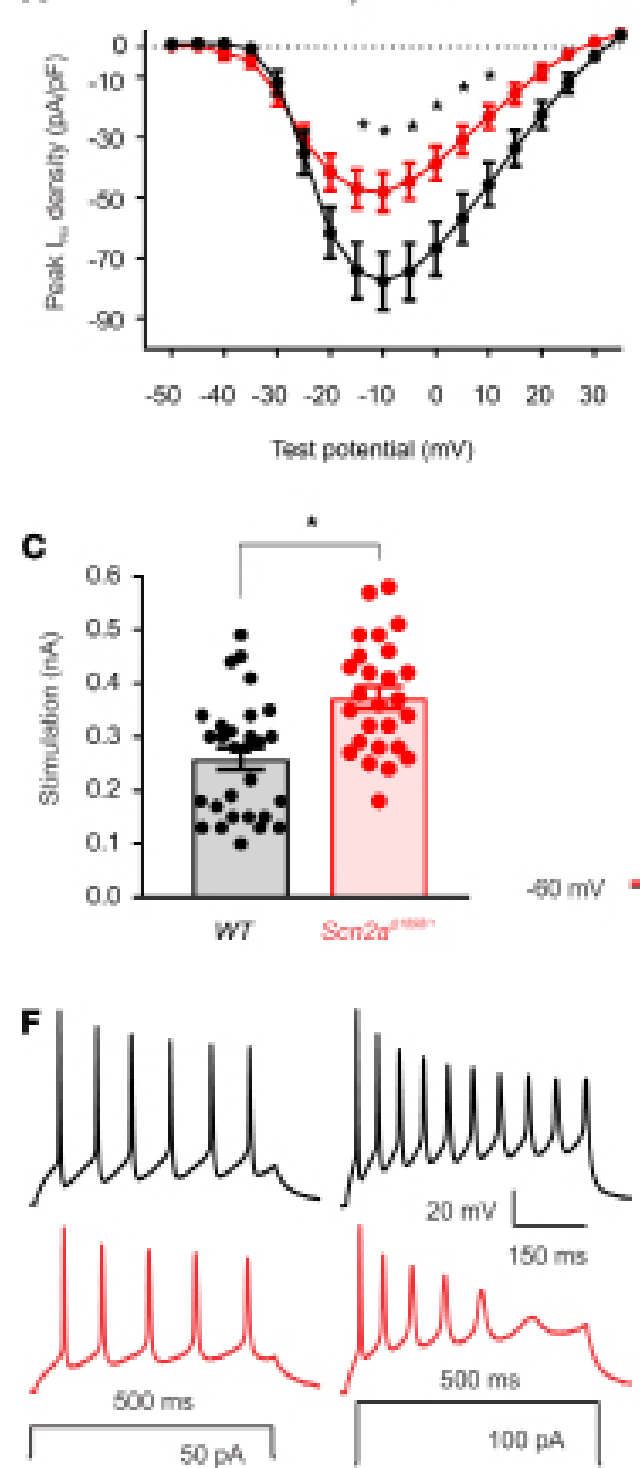

Pyramida
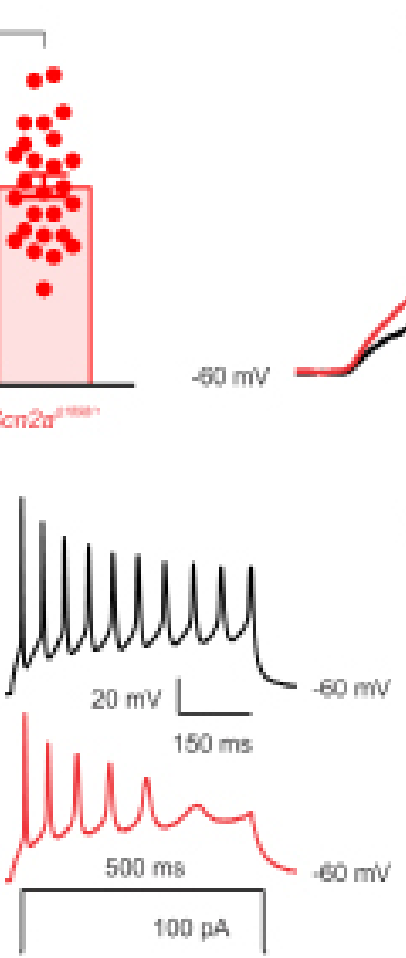

B

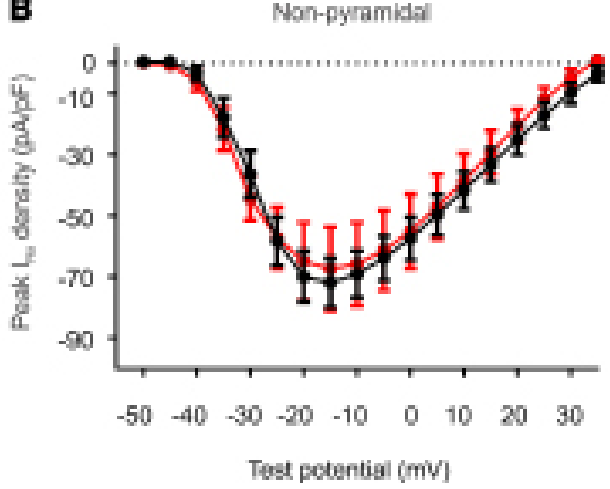

- WT

- Scriariner

Figure 3. Cortical neurons from Scn2 $a^{41898 /+}$ mice display reduced $\mathrm{Na}_{\mathrm{v}}$ channel current and reduced excitability. (A) Current-voltage relationship for

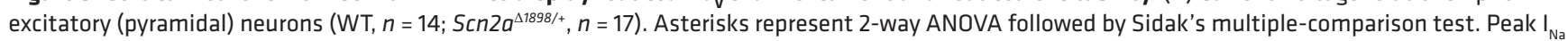
density $\times$ genotype, $\mathrm{F}_{(16,464)}=6.73, P<0.0001$. (B) Current-voltage relationship for inhibitory (nonpyramidal) neurons (WT, $\left.n=12 ; 5 \mathrm{cn} 2 a^{\Delta 1898 /+}, n=12\right)$. (C) Stimulation threshold to elicit action potentials in cultured cortical neurons isolated from WT $(n=29)$ or $\operatorname{Scn} 2 a^{\Delta 1898 /+}(n=26)$. Asterisks represent unpaired $t$ test, $\mathrm{t}_{(53)}=3.961, P=0.0002$. (D) Exemplar action potentials from WT or Scn2a $a^{\Delta 1898 /+}$ elicited at threshold stimulation. (E) Exemplar action potentials from WT or Scn2 $a^{\Delta 1898 /+}$ elicited at a stimulation intensity $\left(0.4 \pm 0.03 \mathrm{nA}\right.$ and $0.6 \pm 0.02 \mathrm{nA}$, for WT and $\operatorname{Scn} 2 a^{\Delta 1898 /+}$, respectively) that elicits the maximal amplitude. (F) Exemplar evoked action potential trains elicited from WT $(n=23)$ or $\operatorname{Scn} 2 a^{\Delta 1898 /+}(n=27)$ with 500 ms current injection of 50 pA or 100 pA. The resting membrane potential is indicated (bottom right). (C) Latency of first spike at minimum stimulation intensity. Asterisks represent unpaired $t$ test, $\mathrm{t}_{(48)}=2.135, P=0.038$. $(\mathbf{H})$ The number of evoked action potentials for the indicated intensity of current injection. Asterisks represent 2-way ANOVA followed by Sidak's multiple-comparison test. Spike number $\times$ genotype, $F_{(11,528)}=6.693, P<0.0001$.

and found that the threshold to elicit APs in cultured Scn2a $a^{\Delta 1898 /+}$ pyramidal cortical neurons was significantly higher than that needed in WT neurons (Figure 3C). Moreover, the AP shape (Figure 3D) and kinetic parameters (Table 1) differed. Although our qPCR data (Figure 2, D and E) demonstrate the absence of transcriptional compensation from other $\mathrm{CNS} \mathrm{Na}$ channels, we cannot exclude compensatory changes from other $\mathrm{Na}^{+}$ channels inserted into specific cellular locations normally dominated by $\mathrm{Na}_{\mathrm{v}} 1.2$, nor by other, non- $\mathrm{Na}^{+}$channel ionic currents that underlie the AP. We attempted to assess the compensation from non- $\mathrm{Na}^{+}$channel ionic currents by analyzing APs elicited by a strong stimulus designed to overcome the relative $\mathrm{Na}_{\mathrm{v}} 1.2$ channel deficit in Scn $2 a^{\Delta 1898 /+}$ neurons. For a stimulus that elicited a maximal amplitude AP, we no longer observed a difference in the AP amplitude between $\operatorname{Scn} 2 a^{\Delta 1898 /+}$ and WT littermate control neurons, suggesting that the reduced 
Table 1. Action potential induced with minimum intensity of 5 ms depolarization step.

\begin{tabular}{lccccccccc}
\hline & RMP (mV) & AMP (mV) & TH (mV) & AP $_{\mathbf{5 0}}(\mathbf{m s})$ & RT (ms) & RS (mV/ms) & DT (ms) & DS (mV/ms) & $N$ \\
WT & $-63 \pm 0.9$ & $96 \pm 2.1$ & $-38 \pm 1.2$ & $2.5 \pm 0.1$ & $7.0 \pm 0.4$ & $8.2 \pm 0.5$ & $6.5 \pm 1.0$ & $21.5 \pm 2.5$ & 29 \\
Scn2 $a^{41898 /+}$ & $-64 \pm 0.5$ & $82 \pm 3.0^{A}$ & $-34 \pm 0.7^{A}$ & $3.4 \pm 0.3^{A}$ & $7.3 \pm 0.2$ & $6.9 \pm 0.4$ & $10.6 \pm 1.6$ & $11.1 \pm 2.2^{A}$ & 26
\end{tabular}

RMP, resting membrane potential; AMP, amplitude; TH, threshold, AP50, half width; RT, $10 \%-100 \%$ rise time; RS, $10 \%-100 \%$ rise slope; DT, $100 \%-10 \%$ decrease time; DS, 100\%-10\% decrease slope. $N$, number. ${ }^{A}$ WT versus Scn2 $2 a^{\Delta 1898 /+}, P<0.05$ (multiple $t$ tests corrected for multiple comparisons using the Holm-Sidak method).

AP amplitude in $S c n 2 a^{\Delta 1898 /+}$ neurons was derived mainly from the reduced $\mathrm{Na}^{+}$current amplitude (Figure $3 \mathrm{E}$ and Table 2). Furthermore, we observed a marked decrease in the number of spikes elicited from $\operatorname{Scn} 2 a^{\Delta 1898 /+}$ neurons across a range of stimulation intensities and, consistent with the reduced overall $\mathrm{Na}^{+}$channel current amplitude in $\operatorname{Scn} 2 a^{\Delta 1898 /+}$ neurons, the latency to first spike was longer than in WT neurons (Figure 3, F-H). Together, these data show that the $\operatorname{Scn} 2 a^{\Delta 1898 /+}$ pyramidal neurons were less excitable than WT neurons.

Behavioral consequences of a Scn2a severe hypomorphic allele. Having established a $\mathrm{Na}_{\mathrm{v}} 1.2$ loss-of-function defect in $\operatorname{Scn} 2 a^{\Delta 1898 /+}$ forebrain neurons, we investigated whether this mutation conferred consequences on behavior. We first assessed general locomotor activity in a novel open-field arena environment. Mutants of both sexes showed no deficits in locomotion, but rather increased locomotion compared with WT mice (Figure 4A). We then assessed core ASD-associated behaviors, repetitive behavior, and social interaction. Using grooming time as a correlate of repetitive behaviors (22), we observed no genotype-specific differences in either males or females (Figure 4B). We then assayed sociability in a 5-minute, 3-chamber social interaction test. Both male and female WT controls and Scn2 $a^{\Delta 1898 /+}$ mice spent more time with a novel mouse than with a novel object (Figure 4, C and D). However, male $S c n 2 a^{\Delta 1898 /+}$ mice spent more time with the novel mouse compared with their WT controls (Figure 4D). This was also reflected in higher distance traveled by $\operatorname{Scn} 2 a^{\Delta 1898 /+}$ compared with WT mice in the zone around the novel mouse (Supplemental Figure 4A), with no difference in distance traveled around the object (Supplemental Figure 4A) and other areas of the 3-chamber apparatus (Supplemental Figure 4, B and C). To further explore this effect, we utilized a modified 3-chamber social interaction protocol to monitor sociability and habituation to a novel mouse, typically seen in WT mice across repeated testing sessions (23, 24). A separate cohort of male $S c n 2 a^{\Delta 1898 /+}$ and WT mice underwent an initial 3-chamber social interaction test (the first test) followed by an additional test (same stranger) 3 hours after the first test. As we observed above (Figure 4, C and D), both WT controls and $\operatorname{Scn} 2 a^{\Delta 1898 /+}$ mice showed a social preference during the first test. During the subsequent test, the WT controls showed the expected habituation to the familiar mouse (3 hours afterward; ref. 23), in contrast, the $S_{c n} 2 a^{\Delta 1898 /+}$ mice continued to spend significantly more time with the familiar mouse during the subsequent test (Figure 4E). These data support that $S c n 2 a^{\Delta 1898 /+}$ mice display altered social interaction behavior characterized by sustained time with the social stimulus. Interestingly, human ASD subjects with $S C N 2 A$ mutations were reported to "enjoy physical contact with caregivers" (25). Furthermore, clinical data from the Simons Variation in Individuals Project (VIP) data (v. 3.0) for individuals with $S C N 2 A$ variants whose caregiver completed the Autism Diagnostic Interview-Revised (ADI-R; ref. 26) with a clinician support those observations. In this largest publicly available database of clinical data in patients with $S C N 2 A$ variants (https://www.sfari.org/funded-project/simons-variation-in-individuals-project-simons-vip/), 10 individuals had an $S C N 2 A$ variant and ADI-R data - 7 who were classified as having autism from the Autism Diagnostic Observation Schedule (ADOS; ref. 27), 2 who were classified as nonspectrum, and 1 with missing data. Four of the 10 individuals had a protein truncation variant with a frameshift. The ADI-R includes a

Table 2. Action potential with maximal amplitude by 5 ms depolarization step.

\begin{tabular}{lcccccccc}
\hline & AMP (mV) & TH (mV) & AP $_{\mathbf{5 0}}(\mathbf{m s})$ & RT (ms) & RS (mV/ms) & DT (ms) & DS (mV/ms) & $N$ \\
WT & $111 \pm 2.6$ & $-25 \pm 1.5$ & $2.2 \pm 0.1$ & $4.2 \pm 0.1$ & $20.3 \pm 0.9$ & $5.1 \pm 0.7$ & $29.9 \pm 4.0$ & 29 \\
Scn2a $a^{41898 /+}$ & $105 \pm 2.8$ & $-19 \pm 1.5^{A}$ & $2.6 \pm 0.2$ & $4.3 \pm 0.1$ & $17.8 \pm 0.5$ & $6.8 \pm 0.9$ & $17.5 \pm 2.3$ & 26
\end{tabular}

AMP, amplitude; $\mathrm{TH}$, threshold, $\mathrm{AP}_{50}$, half width; $\mathrm{RT}, 10 \%-100 \%$ rise time; $\mathrm{RS}, 10 \%-100 \%$ rise slope; $\mathrm{DT}, 100 \%-10 \%$ decrease time; $\mathrm{DS}, 100 \%-10 \%$ decrease slope. $N$, number. ${ }^{A} W T$ versus Scn2 $a^{\Delta 1898 /+}, P<0.05$ (Multiple $t$ tests corrected for multiple comparisons using the Holm-Sidak method). 
A

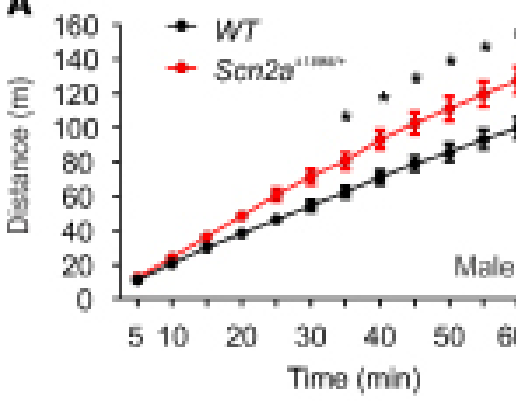

C
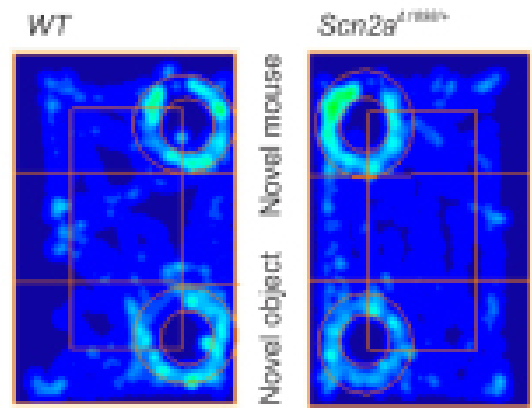

Os
$-3 \mathrm{~m} 59 \mathrm{~s}$

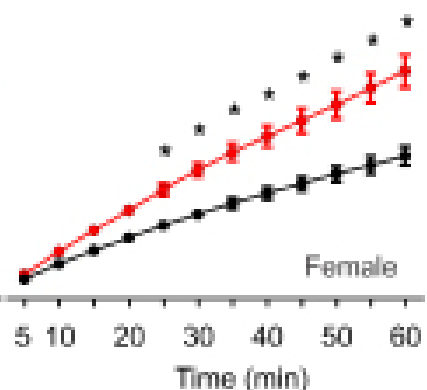

B

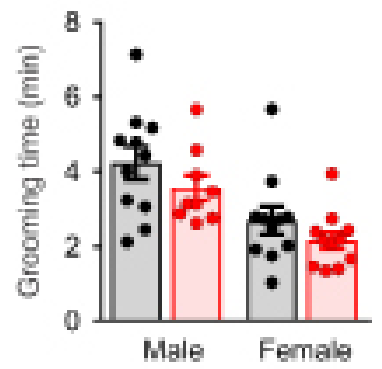

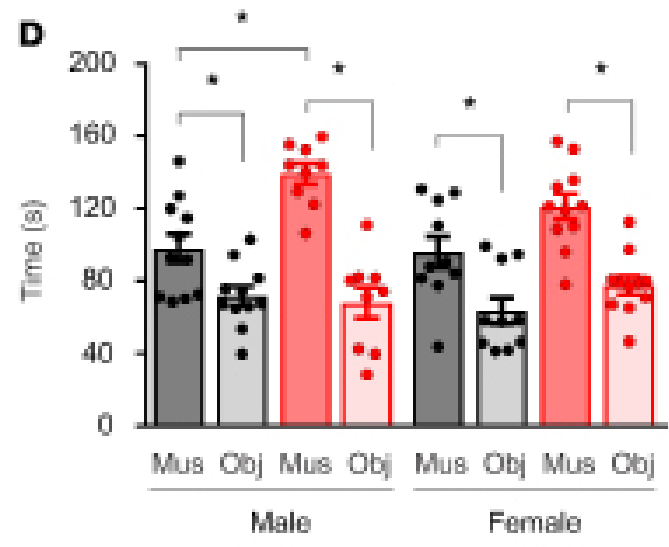

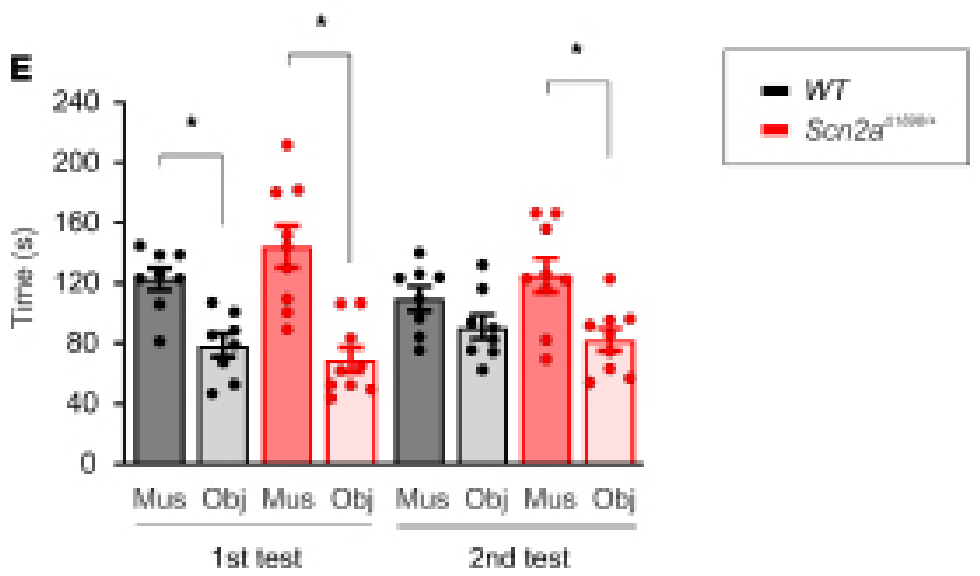

Figure 4. Scn2a $a^{41898 /+}$ mice display hyperactivity in a novel environment and show increased social interactions. (A) Hyperactivity in Scn2a $a^{\Delta 1898 /+}$ male and female mice compared with WT littermate controls in an open field (male: WT, $n=$ 11 and Scn2 $a^{\Delta 1898 /+}, n=9$; female: WT, $n=11$ and Scn2a $\left.a^{\Delta 1898 /+}, n=11\right)$. Asterisks represent 2-way ANOVA followed by Sidak's multiple-comparison test. Distance $\times$ genotype, $F_{(11,198)}=8.278$ for male and $F_{(11,220)}=16.27$ for female, $P<0.0001$. (B) Grooming time. (C) Heatmaps from 3 chamber social interaction tests for WT (male, $n=11$; female, $n=10$ ) and $\operatorname{Scn} 2 a^{\Delta 1898 /+}$ (male, $n=9$; female, $n=11$ ) mice. (D) Time spent with novel mouse (Mus) or novel object (Obj) in the 3-chamber social interaction test. Asterisks represent 2-way ANOVA followed by Tukey's multiple-comparison test. Mus or Obj $\times$ genotype, $F_{(1,36)}=9.963, P=0.003$ for male; $F_{(1.38)}=0.5996, P=0.445$ for female. Mus versus Obj: Tukey's multiple-comparison test; WT, $P=0.04$; Scn2a $a^{\Delta 1898 /+}, P<0.0001$ for male; WT, $P=0.02$; Scn2 $a^{\Delta 1898 /+}, P=0.0004$ for female. (E) Repeated 33 -chamber social interaction tests in a separate cohort of male WT $(n=8)$ and $\operatorname{Scn} 2 a^{\Delta 1898 /+}(n=9)$ mice. Unpaired $t$ test was used to evaluate the difference in time spent between Mus and Obj. Both WT $\left(t_{(14)}=4.174, P=0.0009\right)$ and $\operatorname{Scn} 2 a^{\Delta 1898 /+}\left(t_{(16)}=4.721\right.$, $P=0.0002$ ) mice spent more time with novel Mus over Obj during the first test, but only Scn2a $a^{\Delta 1898 /+}$ mice displayed a social preference 3 hours later (second test) to the familiar Mus $\left(\mathrm{t}_{(16)}=3.149, P=0.0062\right)$.

question regarding social disinhibition that queries whether the child exhibits behavior that is not appropriately modulated according to the social situation, such as inappropriately friendly (i.e., approaching or touching strangers), or if the child is more socially naive than other children (i.e., unable to understand what to say or do in a particular social situation). Caregiver answers were scored on a 4-point scale. Three children scored "occasional disinhibition"; 5 scored "lack of social inhibition"; and 2 scored "marked social disinhibition." 
None reported an absence of disinhibition. Thus, the social interaction abnormality displayed by $\operatorname{Scn} 2 a^{\Delta 1898 /+}$ mice correlates well with observations of humans with $S C N 2 A$ variants and with the inappropriate social disinhibition observed in individuals with $S C N 2 A$ mutations.

Inappropriate social contact with strangers, often characterized as over-friendliness, is a feature of Williams syndrome (WS), a neurodevelopmental disorder caused by hemizygous deletion of 7q11.23 (28). A mouse model of WS shows increased social interaction and lack of habituation to a stranger mouse (29), suggestive of the phenotype we observed in the $S c n 2 a^{\Delta 1898 /+}$ mice. While the underlying genetic defect in subjects with WS is distinct from the loss-of-function mutations in $S C N 2 A$-associated ASD subjects, we considered the possibility that the underlying circuit-level deficits in WS provided guideposts to uncover circuit deficits in ASD subjects with $S C N 2 A$ mutations. A recent review (30) attributed the increased social interaction phenotype in WS subjects to impaired detection of danger, therefore motivating us to test for impaired danger detection in $S c n 2 a^{\Delta 1898 /+}$ mice. We examined performance on an elevated plus maze (EPM) that assesses innate fear and anxiety (31). Both male and female $S c n 2 a^{\Delta 1898 /+}$ mice spent more time, and traveled longer distances, in the open arms than their WT littermate controls (Figure 5, A-C). Neither sex displayed any difference in number of entries to the open arms or closed arms, and there was no difference in time spent and distance traveled in the closed arms (Figure 5, B-D). Therefore, the genotype-specific differences are restricted to the open arms, so the EPM data suggest decreased anxiety-like behavior.

Neuronal synaptic transmission consequences of a Scn2a severe hypomorphic allele. Both $\mathrm{mPFC}$ and amygdala are central hubs integrating distinct functional signals related to higher cognitive and emotional behaviors, including sociability and fear (32-34). Since $S c n 2 a^{\Delta 1898 /+}$ mice display abnormal social interaction and decreased fear-like behavior, we next tested the influence of the decreased neuronal excitability of $\operatorname{Scn} 2 a^{\Delta 1898 /+}$ on synaptic properties and on the E/I balance in brain slices with inclusion of $\mathrm{mPFC}$ or BLA from adult mice. We measured spontaneous excitatory and inhibitory postsynaptic currents (sEPSCs and sIPSCs, respectively) in pyramidal neurons in layer $5 / 6$ of the $\mathrm{mPFC}$ and in the BLA (Supplemental Figure $5, \mathrm{~A}$ and B). The frequency of sEPSCs was reduced in Scn2a $a^{\Delta 1898 /+}$ mice compared with WT littermate controls in both mPFC and BLA pyramidal neurons, suggesting reduced excitatory synaptic input (Figure 6, A, B, and D). The average sIPSC frequency trended toward a decrease but did not reach statistical difference (Figure 6, A, C, and E). On the other hand, sEPSC and sIPSC amplitudes were comparable between WT and Scn $2 a^{\Delta 1898 /+}$ mice (Figure 6, A-E), suggesting no postsynaptic differences between genotypes. These data, combined with the observed effects on elicited APs and excitability in pyramidal neurons, the observed lack of an effect on $\mathrm{Na}^{+}$currents in inhibitory neurons, and the reported absence of a change in inhibitory neuron excitability (21) suggest that neuronal firing was reduced in $\operatorname{Scn} 2 a^{\Delta 1898 /+}$ pyramidal neurons, leading to a reduction in excitatory input to postsynaptic neurons. Overall, this suggests a decrease in excitatory synaptic transmission in $\operatorname{Scn} 2 a^{\Delta 1898 /+}$ neurons.

In vivo neuronal activity consequences of a Scn2a severe hypomorphic allele. We next examined whether the decreased excitability measured in cultured neurons and the decreased synaptic transmission in slices correlated with decreased activity in vivo and with consequences on behavior. We injected a virus encoding the neuronal activity sensor GCaMP6s into mPFC, since circuits from the amygdala to the mPFC have been implicated in fear (35), and tested calcium dynamics in GCaMP6s-expressing neurons with fiber photometry during EPM (Figure 6F). When traveling into an open arm on the EPM, WT mice showed an increase in neuronal activity starting within 1 second of open arm entry, but they showed no increase when entering a closed arm. In contrast, $\operatorname{Scn} 2 a^{\Delta 1898 /+}$ mice displayed no increase in activity when entering either the open or closed arm (Figure 6G). This result echoes the decreased neuronal activity observed in the $S c n 2 a^{\Delta 1898 /+}$ mice in the cellular and slice recordings, and it provides a correlation between abnormal neuronal activity and abnormal behavior in $\operatorname{Scn} 2 a^{\Delta 1898 /+}$ mice.

\section{Discussion}

Although next-generation sequencing shows that de novo loss-of-function protein truncation variants in $S C N 2 A$, often associated with a frameshift, are among the most common genetic associations with ASD $(7,8)$, the mechanisms leading to ASD-associated endophenotypes have not been definitively determined. Here, we demonstrated that an $S c n 2 a$ protein truncation variant that appears to be rapidly degraded reduced the number of functional channels and the amount of $\mathrm{Na}_{\mathrm{v}}$ current in excitatory neurons in which $\operatorname{Scn} 2 a$ is predominantly expressed. Consistent with reduced $\mathrm{Na}_{\mathrm{v}} 1.2$, we found that $\operatorname{Scn} 2 a^{\Delta 1898 /+}$ pyramidal neurons were less excitable. Our observations in mouse neurons, slices, and in vivo echo a report in which knockout of $S C N 2 A$ in neurons derived from induced pluripotent stem cells reduced extracellular spontaneous network activity in glutamatergic neurons (36). 
A
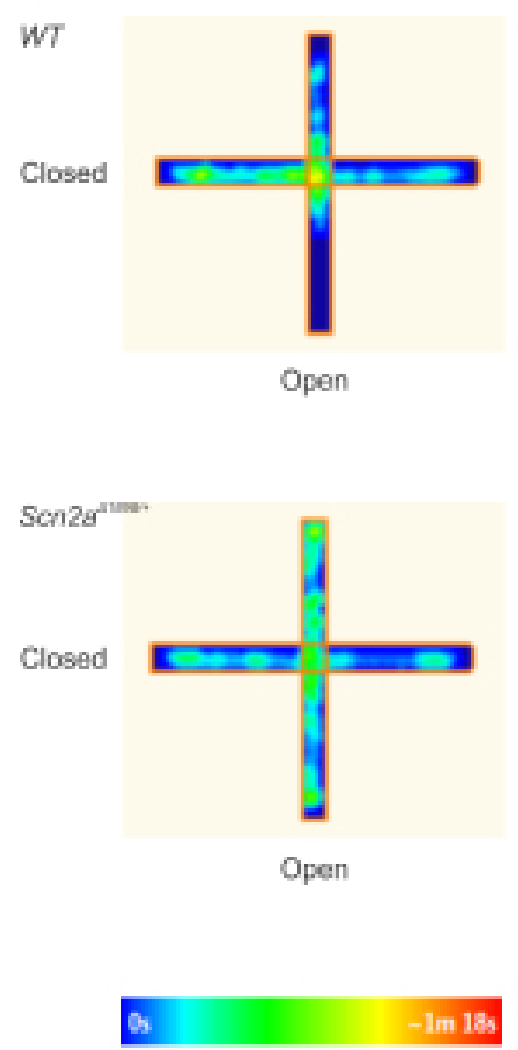

B

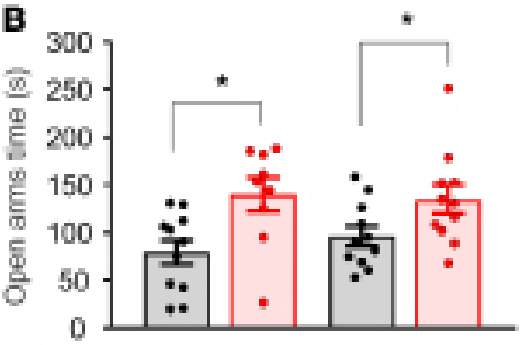

C
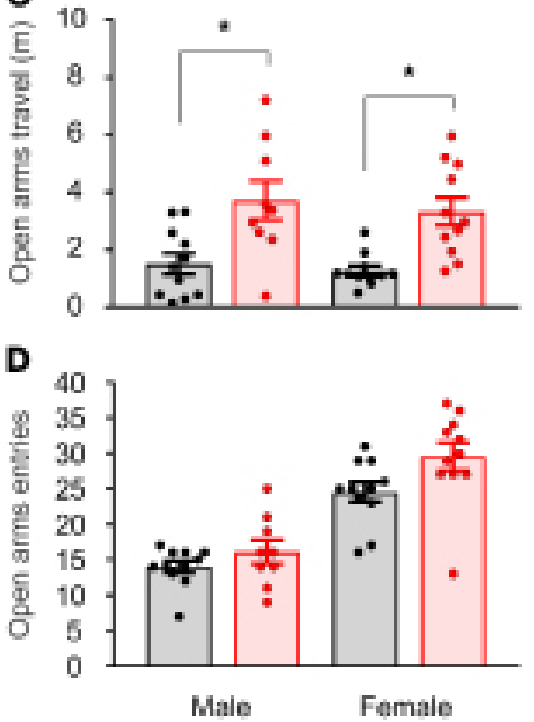
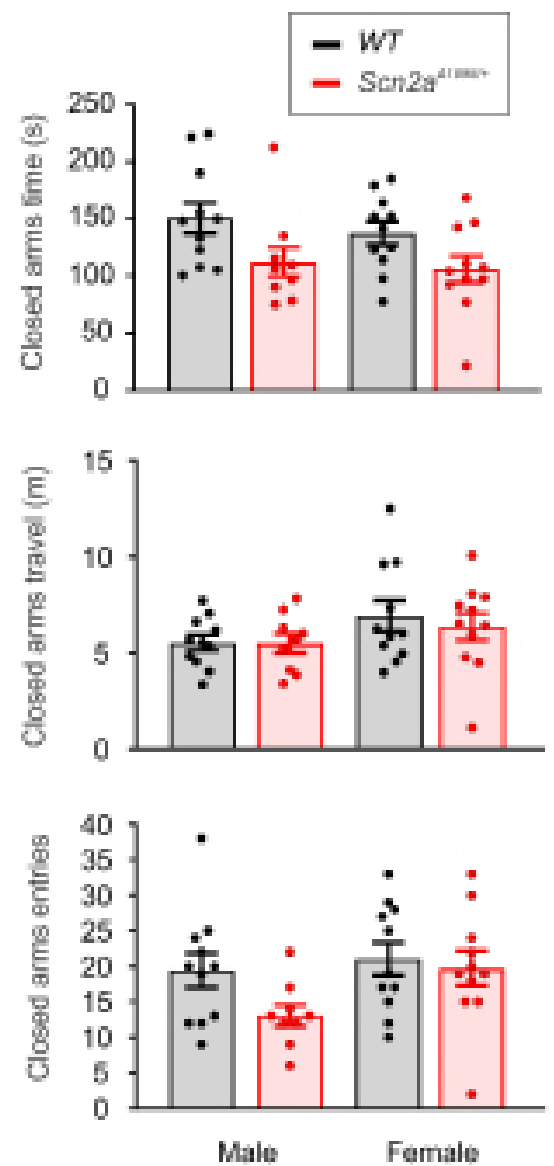

Figure 5. Scn2a $a^{41898 /+}$ mice display increased time and traveled distance on the EPM open arms. (A) Exemplar heatmaps for WT (male, $n=11 ;$ female, $n$ $=11$ ) and $\operatorname{Scn} 2 a^{\Delta 1898 /+}$ (male, $n=9$; female, $n=11$ ) on the EPM. (B) Time spent in the open and closed arms. Asterisks represent unpaired $t$ test; $t_{(18)}=2.886$, $P=0.01$ for male; $\mathrm{t}_{(20)}=2.103, P=0.048$ for female. (C) Distance traveled in the open and closed arms. Asterisks represent unpaired $t$ test; $\mathrm{t}_{(18)}=2.998, P=$ 0.008 for male; $\mathrm{t}_{(20)}=4.07, P=0.001$ for female. (D) Number of entries to the open and closed arms.

Moreover, our analyses reveal correlations between the cellular abnormalities and changes in behavior in $\operatorname{Scn} 2 a^{\Delta 1898 /+}$ mice that, to date, have been elusive when considering the various reported studies of $S c n 2 a^{+/-}$models. Those studies $(11,12,14,15)$ have shown marked discrepancies in the autistic-like and other ASD comorbid behavior phenotypes. For instance, some studies reported increased social interaction $(11,14)$, while others reported a mild decrease $(12,15)$; some studies reported increased grooming in a novel environment $(14,15)$, while another failed to detect abnormal grooming (11). The reasons for the discrepant results, despite using identical or nearly identical models, is not clear. Thus, the utility of comparing a different Scn $2 a$ haploinsufficient model provides an opportunity to define which endophenotypes most likely result from reduced $\mathrm{Na}_{\mathrm{v}} 1.2$ expression.

While we cannot completely rule out a contribution of the additional 26 amino acids generated by the frameshift in the $S c n 2 a^{\Delta 1898 /+}$ mice, our data suggest that the additional 26 amino acids have no discernible effect on $\mathrm{Na}_{\mathrm{v}} 1.2$ channel function; $\mathrm{Na}_{\mathrm{v}} 1.2$ protein with a stop codon inserted at T1898 displayed identical channel properties, as shown in Figure 1. Moreover, the truncated and frameshifted $\mathrm{Na}_{\mathrm{v}} 1.2$ behaves in vivo like a severe hypomorphic allele, as suggested by several lines of evidence. First, the complete absence of surviving $\operatorname{Scn} 2 a^{\Delta 1898 / \Delta 1898}$ pups is consistent with the perinatal lethality of $S c n 2 a^{-1-}$ mice (20). Secondly, our biochemical and electrophysiological analyses suggest little, if any, functional protein from the mutant allele (Figure 2 and Figure 3). Therefore, by demonstrating functionally equivalent biophysical and biochemical consequences of the truncation and the frameshift variant in a heterologous expression system, our data show that the reduced $\mathrm{Na}^{+}$channel function recorded in neurons isolated from $\operatorname{Scn} 2 a^{\Delta 1898 /+}$ mice result from the eliminated $\mathrm{Na}_{\mathrm{v}} 1.2$ protein rather than the introduction of the additional 26 amino acids. Thus, the hypomorphic $S c n 2 a^{\Delta 1898 /+}$ model is representative of ASD-associated mutations in SCN2A, such as D82G or T1420M (10).

With that background, the $S c n 2 a^{\Delta 1898 /+}$ mice displayed an increase in social interaction (consistent with refs. $11,14)$ and an increase in locomotor activity, along with reduced anxiety-like behavior (consistent with refs. 12 , 
A $B E P S C$

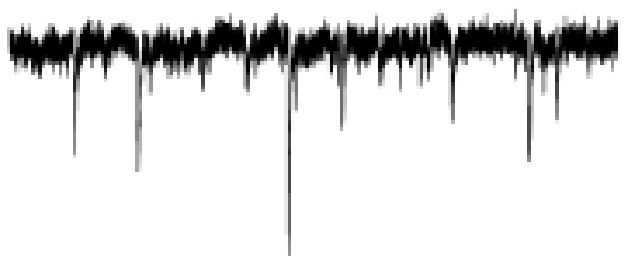

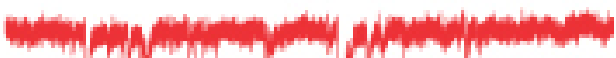

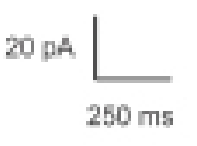

BIPSC

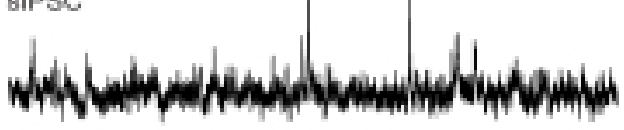

$$
40 \text { pA } \underbrace{\bigsqcup}_{500 \mathrm{~ms}}
$$
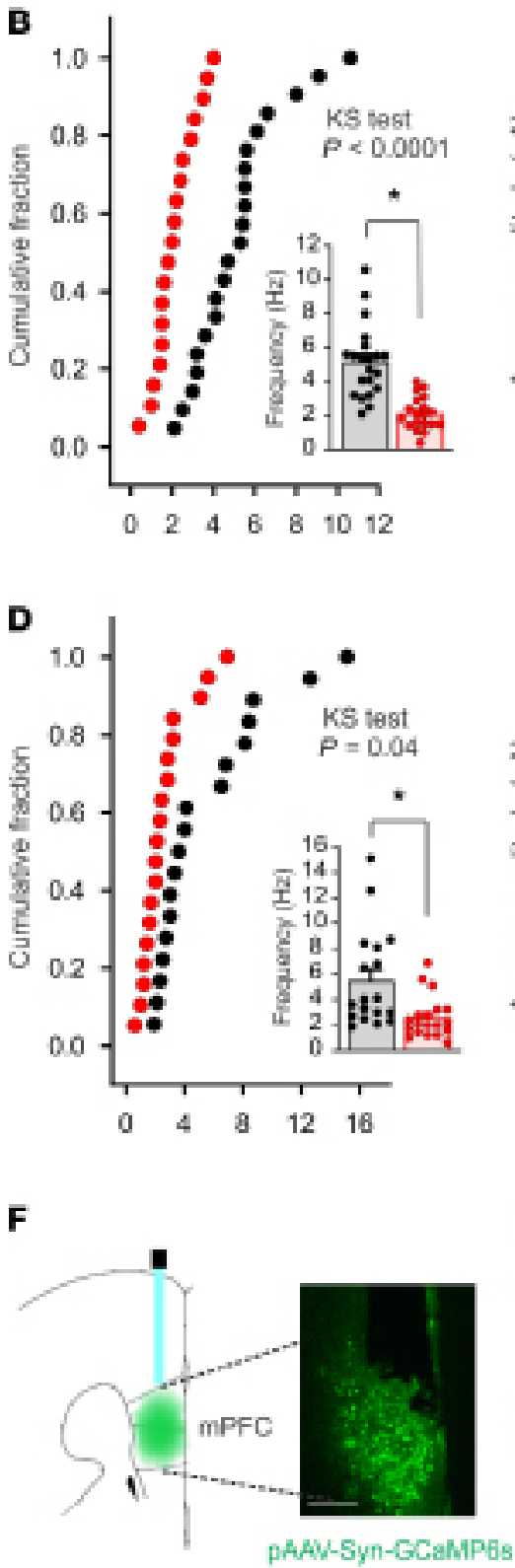
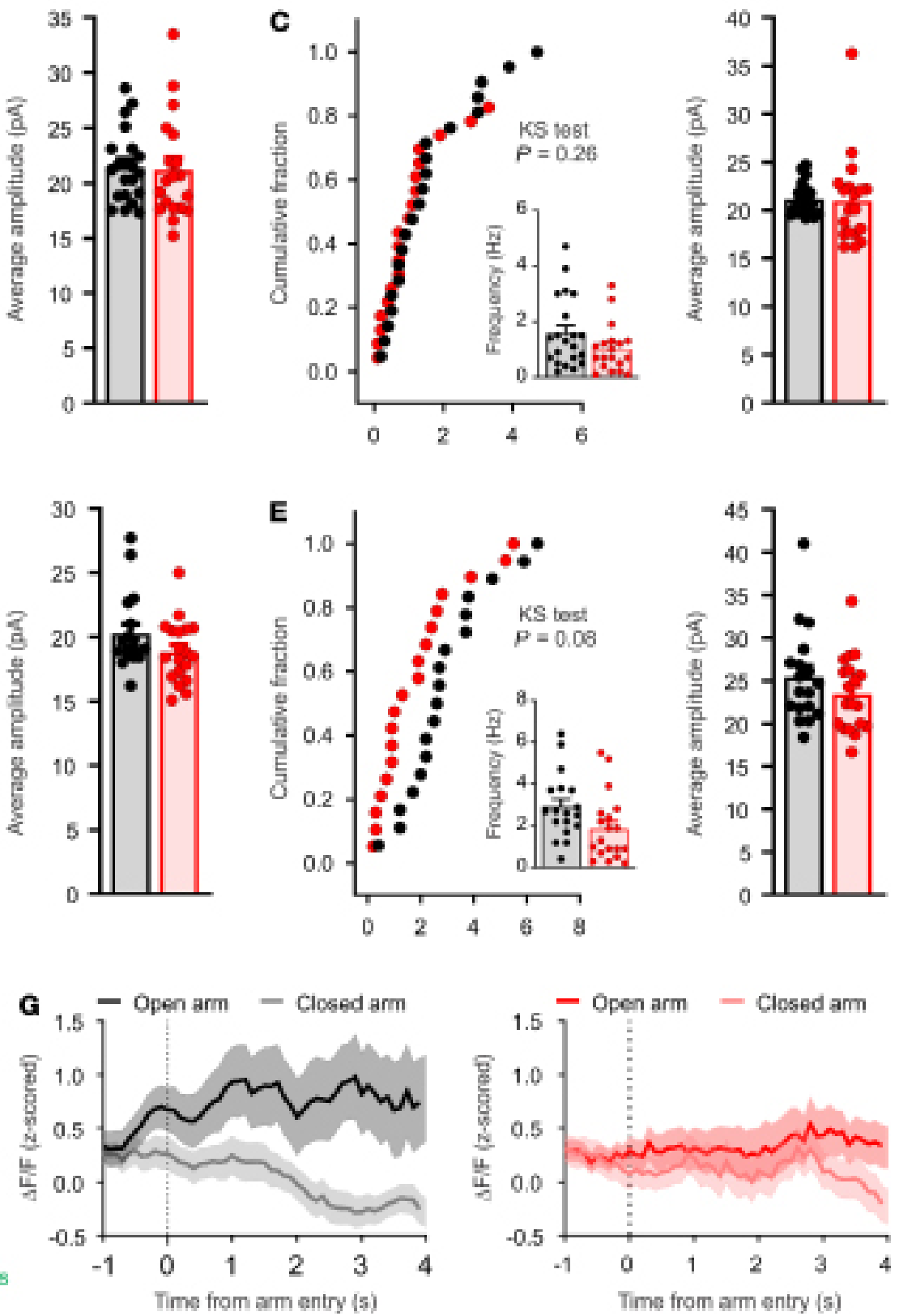
Figure 6. Pyramidal neurons in mPFC and BLA from Scn2 $a^{41898 /+}$ mice display altered excitability and synaptic properties. (A) Exemplar sEPSCs and sIPSCs recorded in pyramidal neurons from Scn2 $2 a^{\Delta 1898 /+}$ and WT mice at holding potential of $-50 \mathrm{mV}$ and $0 \mathrm{mV}$, respectively. WT, black; Scn2 $a^{\Delta 1898 /+}$, red. (B and C) Quantification of frequency and amplitude of sEPSCs and sIPSCs (Scn2a $\left.a^{\Delta 1898 /+}, n=19 ; \mathrm{WT}, n=21\right)$ recorded in layer $5 / 6$ pyramidal neurons in mPFC. Frequency of sEPSCs reduced as shown in both cumulative fraction and average (inset, asterisks represent unpaired $t$ test, $\mathrm{t}_{(38)}=5.691, P<0.0001$ ). (D and $\mathbf{E}$ ) Quantification of frequency and amplitude of sEPSCs and sIEPSCs (Scn2a $a^{\Delta 1898 /+}, n=19 ;$ WT, $n=18$ ) recorded in pyramidal neurons in BLA. Frequency of sEPSCs reduced as shown in both cumulative fraction and average (inset, asterisks represent unpaired $t$ test, $t_{(35)}=3.027, P=0.005$ ). The cumulative frequency distributions were analyzed with the Kolmogorov-Smirnov comparison (KS test) in B-E. (F) Microscopic graph showing the GCaMP6s virus expression and fiber placement in mPFC. (C) Calcium dynamics in GCaMP6s-expressed neurons with fiber photometry recording during EPM. In contrast to WT mice, Scn2a ${ }^{\Delta 1898 /+}$ mice failed to show an increase in fluorescence $\left[\mathrm{Ca}^{2+}\right]$ signal when mice entered the open arms compared with the closed arms.

$14,15)$. We also observed no change in grooming in $\operatorname{Scn} 2 a^{\Delta 1898 /+}$ mice, consistent with the previous report by Shin, et al. (11). Thus, the overlaps with our distinct model suggests validation for those behavior abnormalities as indeed associated with Scn2a haploinsufficiency. Additionally, the hypersocial interaction phenotype, reported by several groups using a 3-chamber social interaction test for various mouse models $(14,29,37-40)$ and specifically in the $\operatorname{Scn} 2 a^{+/-}$model $(11,14)$, appears to be consistent with the inappropriate social approach behavior (i.e., inappropriate social disinhibition) reported in individuals with $S C N 2 A$ variants seen in our analysis of the Simons VIP database. Furthermore, our fiber photometry data suggest a direct link from cellular electrophysiology and a specific behavior in the mouse model.

Having established social disinhibition and decreased anxiety (on the EPM) as phenotypes associated with decreased Scn2a expression, analysis of circuit deficits in WS may serve as a guide for future studies to investigate the consequences of $S c n 2 a$ haploinsufficiency. Functional MRI in individuals with WS showed reduced functional connectivity between the amygdala and the medial prefrontal and orbitofrontal cortex, which was correlated with social disinhibition (41). Recent studies demonstrated that the mPFC makes excitatory projections to principal neurons in the BLA $(42,43)$. We therefore hypothesize that the loss-of-function defects observed in $\mathrm{Na}^{+}$currents within pyramidal neurons from $\operatorname{Scn} 2 a^{\Delta 1898 /+}$ mice, and the consequent reduced excitatory input, impair the excitatory connections from the medial prefrontal to the BLA. This, in turn, would reduce amygdala output. The abnormal behavior was correlated to a reduced neuronal activity in $\mathrm{mPFC}$ in fiber photometry recording in $S c n 2 a^{\Delta 1898 /+}$ mice. Consistent with this hypothesized reduced amygdala output, the $S c n 2 a^{\Delta 1898 /+}$ mice demonstrated an impairment in danger detection, as observed on the EPM. The similarities among the social disinhibition in humans with $S C N 2 A$ variants, the reported enjoyment of interactions with caregivers for humans with $S C N 2 A$ variants, and the observed social phenotypic abnormality in the Scn $2 a^{\Delta 1898 /+}$ mouse model suggest a testable cellular-to-endophenotype connection for future studies. Future circuit level analyses will allow us to test this hypothesis in detail, but the data here suggest that a neocortical $\mathrm{E} / \mathrm{I}$ imbalance, whether an increased or decreased ratio, is a substrate for ASD-associated endophenotypes. It is possible that the heterogeneous changes in $\mathrm{E} / \mathrm{I}$ imbalance (higher or lower) and the consequent alteration in brain network in the temporal and spatial scales could be associated with different manifestations of behavior, which is reflected by the clinical heterogeneity of autistic patients.

While decreased excitability in the principal neurons expressing Scn $2 a$ with decreased frequency of sEPSCs provides a rationale for that proposed deficit in the prefrontal cortex to amygdala circuit, additional factors may also contribute. We did not observe a significant difference in frequency of sIPSCs between WT and Scn $2 a^{\Delta 1898 /+}$ mice, nor a difference in $\mathrm{Na}^{+}$currents within inhibitory neurons, although the average frequency of sIPSCs showed a trend to decrease. The subtle reduction in sIPSCs could represent a homeostatic response aimed at maintaining the proper E/I balance through local synaptic adaptions and network-wide adjustments (44), but this change in inhibitory input could not restore the overall deficit in excitatory activity of pyramidal neurons.

We found that the difference in the AP amplitude between $S c n 2 a^{\Delta 1898 /+}$ and WT littermate control neurons was no longer observed with a stimulus that elicited a maximal AP amplitude, suggesting that the reduced AP amplitude with a smaller stimulus derived mainly from the reduced $\mathrm{Na}^{+}$current amplitude. However, the higher intensity stimulus did not correct the AP threshold, suggesting that the observed differences in AP between WT and $S c n 2 a^{\Delta 1898 /+}$ (Figure 3E and Table 2) also reflected compensation by other non- $\mathrm{Na}^{+}$channel ionic currents. Likely, other homeostatic mechanisms, at the cellular and circuit levels, are activated even though those mechanisms appear insufficient to rescue the hypersocial behavior or the decreased anxiety-like behavior and/ or impairment of danger detection as indicated by the EPM.

Excitatory neurons within the cortex express both $\mathrm{Na}_{\mathrm{v}} 1.2$ and $\mathrm{Na}_{\mathrm{v}} 1.6$, yet mutations in $S C N 8 A$ that encodes $\mathrm{Na}_{\mathrm{v}} 1.6$ have not been associated with ASD. That expression of $\mathrm{Na}_{\mathrm{v}} 1.6$ is not prominent until later developmental stages, when critical neural circuits are already established; this provides at least one likely reason why $S C N 8 \mathrm{~A}$ 
mutations have not been associated with ASD. Consistent with a later role in development for $\mathrm{Na}_{\mathrm{v}} 1.6$, we did not observe a compensatory increase in $\operatorname{Scn} 8$ a mRNA, or any other CNS Na ${ }^{+}$channel, in the P6 and adult $S c n 2 a^{\Delta 1898 /+}$ mice. This absent compensatory response to a reduction in $\mathrm{Na}_{\mathrm{v}} 1.2$ protein and $\mathrm{Na}_{\mathrm{v}} 1.2$-dependent $\mathrm{Na}^{+}$current in the Scn2a $a^{\Delta 1898 /+}$ mice may offer an additional explanation for why loss-of-function SCN2A mutations have been identified as one of the most common genetic associations with ASD.

In summary, the cellular electrophysiology data and the behavior data displayed by the $\operatorname{Scn} 2 a^{\Delta 1898 /+}$ mice, and the resulting protein truncation variant $\mathrm{Na}_{\mathrm{v}} 1.2^{\Delta 1898}$, provide valuable tools to investigate the molecular mechanisms by which $S C N 2 A$ mutations cause abnormal social behaviors and offer opportunities to explore therapeutic options for one of the most commonly affected ASD-associated loci.

\section{Methods}

Frameshift generation. The $S c n 2 a^{\Delta 1898 /+}$ mouse line with a frameshift (p.T1898NfsX27) in 1 allele of Scn2a (Figure 1A) was created by CRISPR/Cas9 by the Transgenic Mouse Shared Resource at Duke University School of Medicine (Durham, North Carolina, USA) during an attempt to create a $\operatorname{Scn} 2 a^{R 1903 C}$ knock-in mutation. The guide sequence (5'-GATAGCGTCTGTAAGCTCGCTGG-3') was identified using the online tool at http://crispr. mit.edu/. The guide and repair oligonucleotides (5'-GCTCTTCGAATCCAGATGGAAGAGCGGTTCATGGCTTCCAATCCСTCCAAGGTCTCTTATGAGCCCATTACCACCACTCTGAAGTGCAAACAAGAGGAGGTGTCTGCTATTGTCATACAGCGAGCTTACAGACGCTATCTTCTGAAACAGAAAGTTAAGAAGGTTTCGTCTATATATAAAAAAGACAAGGGTAAAGAAGA-3'; the underlined "T" introduces a $C>$ T point mutation, and the underlined " $\mathrm{A}$ " disrupts the PAM sequence and creates a silent mutation within the coding region) were synthesized at Integrated DNA Technologies Inc. and subcloned into pX330 using standard cloning procedures, and they were produced from recombinant pX330 plasmid using MEGAshortscript (Ambion) following the manufacturer's protocol. sgRNAs were tested in vitro using Guide-it sgRNA Screening System (Clontech Laboratories) following the manufacturer's protocol. The reagents were injected into B6SJLF1/J oocytes to obtain pups that were sequenced by sequencing genomic DNA by PCR. A line with the off-target p.T1898NfsX27 (Supplemental Figure 1) in 1 allele was selected for further study.

Heterologous expression system analyses of voltage-gated currents and biotinylation. QuikChange Site-Directed Mutagenesis kit (Agilent Technologies) was used to generate p.T1897NfsX27 (Na $1.2^{\Delta 1897}$, equivalent to mouse p.T1898NfsX27) in a human SCN2A cDNA subcloned into pCI-Neo. The truncation mutant $\left(\mathrm{Na}_{\mathrm{v}} 1.2^{1897-S T O P}\right)$ was also generated with QuikChange, by inserting a stop codon after T1897 in the SCN2A cDNA.

Biotinylation analysis. HEK293 cells were cultured in DMEM with $10 \%$ FBS in a $37^{\circ} \mathrm{C}$ incubator with $5 \% \mathrm{CO}_{2}$ and were grown in $100 \mathrm{~mm}$ culture dishes. Plasmids encoding $\mathrm{WT} \mathrm{Na} \mathrm{v}_{\mathrm{v}} 1.2\left(\mathrm{Na}_{\mathrm{v}} 1.2^{\mathrm{WT}}\right), \mathrm{Na}_{\mathrm{v}} 1.2^{\Delta 1897}$, $\mathrm{Na}_{\mathrm{v}} 1.2^{1897-\text { STOP }}$, or empty vector $(8 \mu \mathrm{g}$ ) were cotransfected with $\operatorname{Scn} 1 b(4 \mu \mathrm{g})$ using Lipofectamine 2000 (Thermo Fisher Scientific). Forty-eight hours after transfection, cultured HEK293 cells were washed with ice cold PBS and incubated in $1 \mathrm{mg} / \mathrm{mL}$ sulfo-NHS-SS-Biotin (Thermo Fisher Scientific) in PBS for 30 minutes at $4^{\circ} \mathrm{C}$. Cells were washed twice with $100 \mathrm{mM}$ glycine to quench the reaction and then were lysed in lysis buffer $(\mathrm{NaCl}$ $150 \mathrm{mM}$, Tris $50 \mathrm{mM}$, Triton 1\%, and Roche protease inhibitor 1 tablet/7.5 mL, pH 7.4). After rocking for 30 minutes at $4^{\circ} \mathrm{C}$, lysates were passed through 18 gauge and then 25 gauge needles for 25 passes each; they were then centrifuged at $17,000 \mathrm{~g}$ for 15 minutes at $4^{\circ} \mathrm{C}$. Supernatants were collected and protein concentration was quantified using a BCA Protein Assay Kit (Thermo Fisher Scientific). Supernatants were incubated and rocked with NeutrAvidin agarose resin (Thermo Fisher Scientific) overnight at $4^{\circ} \mathrm{C}$. The following day, the beads were washed 3 times with lysis buffer, resuspended in LDS sample buffer (Thermo Fisher Scientific) containing 50 $\mathrm{mM}$ DTT, and heated to $95^{\circ} \mathrm{C}$ for 3 minutes. About $20 \mathrm{~g}$ of protein were dissolved with LDS sample buffer and separated on Novex WedgeWell 8 to 16\% Tris-glycine gels (Thermo Fisher Scientific) and transferred to PVDF blotting membrane (GE Healthcare Life Sciences). The membrane was immunoblotted with an anti-pan sodium channel antibody (1:1000; MilliporeSigma, S8809), anti-transferrin receptor (1:1000; Thermo Fisher Scientific, 13-6800) and anti- $\beta$-actin (1:5000; MilliporeSigma, A1978) antibodies and detected by chemiluminescence. Images were captured using Kodak Image Station $4000 \mathrm{R}$ and quantified using ImageJ (NIH).

Immunoblotting of brain cortex. About $80 \mathrm{mg}$ neonatal (P6) and adult ( $\sim$-month-old) brain cortices were homogenized with glass homogenizer in RIPA Buffer (Thermo Fisher Scientific) containing $\mathrm{NaCl} 150 \mathrm{mM}$, Tris-HCl 25 mM, NP-40 1\%, sodium deoxycholate 1\%, SDS 0.1\%, ThermoHalt protease inhibitor, and Halt phosphatase inhibitor, pH 7.6 (Thermo Fisher Scientific). After rocking for 2 hours at $4^{\circ} \mathrm{C}$, lysates were passed through 18 gauge and then 25 gauge needles for 25 passes each; they were then centrifuged at $17,000 \mathrm{~g}$ for 15 minutes at $4^{\circ} \mathrm{C}$. Supernatants were collected, and protein concentration was quantified using a BCA Protein 
Assay Kit (Thermo Fisher Scientific). Protein $(30 \mu \mathrm{g})$ was separated on Novex WedgeWell 8 to 16\% Tris-glycine gels (Thermo Fisher Scientific) and transferred to PVDF blotting membrane (GE Healthcare Life Sciences). The membrane was immunoblotted with anti-pan sodium channel antibody (1:1000; MilliporeSigma, S8809), anti-Na 1.2 sodium channel (1:200; NeuroMab, 75-024; Alomone Labs, ASC-002), and anti- $\beta$-actin (1:5000; MilliporeSigma, A1978) antibodies. The blots were visualized by chemiluminescence, and images were captured using ChemiDoc Touch Imaging System (Bio-Rad) and quantified using ImageJ (NIH).

IHC of brain cortex. Brains were rapidly removed from newborn pups and immersed in $0.5 \%$ paraformaldehyde in $0.1 \mathrm{M}$ PBS for 2 hours at $4^{\circ} \mathrm{C}$ followed by an overnight immersion in $30 \%$ sucrose in PBS. Then, brains were embedded in OCT compound and stored at $-80^{\circ} \mathrm{C}$ overnight. Brain tissue was sectioned to 10 $\mu \mathrm{m}$ slices using a cryostat, and slices were stored overnight in $-20^{\circ} \mathrm{C}$. Brain sections were thawed for 5 minutes in room temperature, rinsed with $0.1 \mathrm{M}$ PBS, and incubated with primary antibodies: a custom rabbit $\mathrm{Na}_{\mathrm{v}} 1.2$ (1:500) designed by YenZym LLC and mouse ankyrin G (1:200; NeuroMab, N106/36) in PBS with $5 \%$ bovine albumin serum and $0.3 \%$ Triton X-100 overnight at $4^{\circ} \mathrm{C}$. Subsequently, after slices were rinsed with $0.1 \mathrm{M}$ PBS 3 times each for 5 minutes, the slices were incubated with secondary antibodies Alexa Fluor 488 anti-rabbit and Alexa Fluor 647 anti-mouse $\operatorname{IgG}(1: 500)$ at room temperature $\left(25^{\circ} \mathrm{C}\right)$ for 1 hour. Slides were then washed with $0.1 \mathrm{M}$ PBS for 3 times each for 5 minutes and were mounted using mounting media (Vector Laboratories) and sealed with a glass cover slip. Slides were kept at $4^{\circ} \mathrm{C}$ for 2 hours. Stained brain slices were imaged using a confocal microscope (Zeiss LSM 880), and $Z$ stacks were obtained with $0.5 \mu \mathrm{m}$ per slice. Images were merged and analyzed using ImageJ software.

$q P C R$. Total mRNA was purified from neonatal (3-6 days) and adult ( $\sim 5$-month-old) brain cortices using RNAeasy Plus Mini kit (Qiagen), and it was reverse transcribed to single-stranded cDNA library using iScript cDNA Synthesis Kit (Bio-Rad). Primers for qPCR were 5'-CACTCATTATTCAGCATGTTAATCATGTGC-3' (forward) and 5'-CGATGGTCTTCAGGCCTGGAATG-3' (reverse) for Scn1a; 5'-CCAGACTGGACAAAGAATGTGGAGTATAC-3' (forward) and 5'-CGATGGTCTTCAGGCCTGGAAT-3' (reverse) for Scn2a; 5'-CCTGACTGGACGAAGAATGTAGAGTACAC-3' (forward) and 5'-CGATGGTCTTTAAACCTGGAATGACTG-3' (reverse) for $S c n 3 a ;$ 5'-CATTCAGTCTTCAGCATGATCATCATGTG-3' (forward) and 5'-CGATTGTCTTCAGGCCTGGGAT-3' (reverse) for Scn8a; and 5'-CCTGGAGAAACCTGCCAAGTATGATG-3' (forward) and 5'-CTGTAGCCGTATTCATTGTCATACCAGG-3' (reverse) for GAPDH. qPCR (a total 40 cycles) was performed using the QuantStudio 3 (Applied Biosystems). The relative amount of target message in each reaction was determined from the detection threshold cycle number (Ct), which was normalized to the $\mathrm{Ct}$ for GAPDH obtained simultaneously.

Forebrain cortex neuron cultures. Forebrain cortices from 1- to 3-day newborn WT and p.T1898NfsX27 $\left(\operatorname{Scn} 2 a^{\Delta 1898 /+}\right)$ mice were dissociated through enzymatic treatment with $0.25 \%$ trypsin and subsequent trituration. The cells were plated on glass coverslips previously coated with poly-D-lysine and laminin in 12-well cell culture plate in the density of $170,000 / \mathrm{mL}$. The cortical cells were grown in neurobasal A medium (Thermo Fisher Scientific) supplemented with B-27 2\%, glutamine $2 \mathrm{mM}$, heat-inactivated FBS 10\%, and penicillin/streptomycin $1 \%$ in $5 \% \mathrm{CO}_{2}$ incubator at $37^{\circ} \mathrm{C}$ overnight; then, this medium was replaced by one containing B-27 $2 \%$, glutamine $0.5 \mathrm{mM}$, heat-inactivated FBS $1 \%$, uridine $70 \mu \mathrm{M}$, and 5-fluorodeoxyuridine $25 \mu \mathrm{M}$. Cultured neurons were used for electrophysiology 5 days in vitro (DIV) after plating, and recordings were performed on either pyramidal or nonpyramidal shaped neurons selected based on the shape of their cell body and dendritic pattern (Supplemental Figure 2, A and B).

Acute slice preparation. Coronal brain slices were prepared from male and female $\operatorname{Scn} 2 a^{\Delta 1898 /+}$ mice and their respective littermates (8-10 weeks old). Animals were anesthetized with $1.25 \%$ Avertin (250 mg/ $\mathrm{kg}$; i.p.) and then transcardially perfused with a cold sucrose-based solution. This solution contained (in $\mathrm{mM}$ ): sucrose 220, $\mathrm{KCl} 2.5, \mathrm{MgSO}_{4} 12, \mathrm{CaCl}_{2} 0.5, \mathrm{NaH}_{2} \mathrm{PO}_{4} 1.25, \mathrm{NaHCO}_{3}$ 26, glucose 10, HEPES 10, and sodium pyruvate 3 ( $\mathrm{pH} 7.4$ ). After decapitation, the brain was transferred quickly into the above-mentioned ice-cold sucrose based cutting solution bubbled with $95 \% \mathrm{O}_{2}$ and $5 \% \mathrm{CO}_{2}$. Coronal brain slices (300 $\mu \mathrm{m}$ ) including $\mathrm{mPFC}$ or BLA were prepared using a Leica VT1200S vibratome (Leica), and they were incubated in a BSK-2 brain slice keeper (Automate Scientific) containing oxygenated artificial cerebrospinal fluid (aCSF) at $35^{\circ} \mathrm{C}$ for 40 minutes. Afterward, the slices were maintained at room temperature at least 30 minutes before use.

Electrophysiology. Whole-cell sodium $\left(\mathrm{Na}^{+}\right)$currents from HEK293 cells and cultured neurons, and sEPSC and sIPSC from acute brain slices, were recorded in the voltage patch-clamp configuration, and APs from cultured neurons were recorded in the current-clamp configuration with an Axopatch 200B amplifier 
(Molecular Devices) and sampled at $10 \mathrm{kHz}$ and filtered at $2 \mathrm{kHz}$. Data were analyzed with Axon Clampfit (Molecular Devices) or Mini Analysis (Synaptosoft Inc.).

For $\mathrm{Na}^{+}$currents recording in $\mathrm{HEK}$ cells, the pipette internal solution contained the following (in $\mathrm{mM}$ ): $\mathrm{CsCl}$ 16, CsF 110, $\mathrm{NaCl} 10, \mathrm{CaCl}_{2}$ 0.5, $\mathrm{MgCl}_{2}$ 1, EGTA 10, HEPES 10, $\mathrm{Na}_{2}$-APT 2 (pH 7.3), with CsOH. The external solution contained (in $\mathrm{mM}$ ): $\mathrm{NaCl} 120, \mathrm{KCl} 5.4, \mathrm{CaCl}_{2}$ 1.8, $\mathrm{MgCl}_{2}$ 1, HEPES 10, glucose 10 , tetraethylammonium chloride (TEA-Cl) $20(\mathrm{pH} 7.4)$, with $\mathrm{NaOH}$. For $\mathrm{Na}^{+}$currents recording in cultured neurons, the pipette internal solution contained (in $\mathrm{mM}$ ): $\mathrm{CsCl} 50, \mathrm{CsF} 35$, L-aspartic acid 55, $\mathrm{NaCl} 10$, EGTA 5, $\mathrm{MgCl}_{2}$ 1, Mg-ATP 4, $\mathrm{Na}_{2}$-GTP 0.4, and HEPES 10 (pH 7.3), with CsOH. External solution contained (in mM): $\mathrm{NaCl} 100, \mathrm{KCl}$ 5, HEPES 20, $\mathrm{CaCl}_{2} 2, \mathrm{MgCl}_{2}$ 2, glucose 30, TEA-Cl 20, 4-aminopyridine 2 , $\mathrm{CdCl}_{2}$ 0.5, APV 0.05, DNQX 0.02, and bicuculline 0.02 (pH 7.4), with $\mathrm{NaOH}$. For AP initiation in cultured neurons, the pipette internal solution contained (in $\mathrm{mM}$ ): potassium gluconate $130, \mathrm{KCl} 10, \mathrm{MgCl}_{2}$, EGTA 0.6, HEPES 5, $\mathrm{CaCl}_{2}$ 0.06, phosphocreatine disodium 10, Mg-ATP 2, $\mathrm{Na}_{2}$-GTP 0.2, and creatine phosphokinase $50 \mathrm{U} / \mathrm{mL}$ ( $\mathrm{pH} 7.2$ ), adjusted with $\mathrm{KOH}$. The external solution contained (in $\mathrm{mM}$ ): $\mathrm{NaCl} 119, \mathrm{KCl} 5$, HEPES 20, $\mathrm{CaCl}_{2} 2, \mathrm{MgCl}_{2}$ 2, glucose 30, APV 0.05, DNQX 0.02, and bicuculline 0.02 ( $\mathrm{pH} 7.3$ ), adjusted with $\mathrm{NaOH}$. For sEPSCs and sIEPSCs recording from brain slices, the pipette internal contained (in $\mathrm{mM}$ ): potassium gluconate $125, \mathrm{KCl} \mathrm{10,} \mathrm{MgCl}_{2}$ 5, EGTA 0.6, $\mathrm{HEPES} \mathrm{5,} \mathrm{CaCl}_{2}$ 0.06, phosphocreatine disodium 10, Mg-ATP 2, $\mathrm{Na}_{2}$-GTP 0.2, creatine phosphokinase $50 \mathrm{U} / \mathrm{mL}$, and lidocanine N-ethyl bromide 5 (pH 7.2), adjusted with $\mathrm{KOH}$. The aCSF contained (in $\mathrm{mM}$ ); $\mathrm{NaCl} 126, \mathrm{KCl} 2.5, \mathrm{NaH} 2 \mathrm{PO}_{4} 1.25, \mathrm{NaHCO}_{3} 26, \mathrm{CaCl}_{2}$ $2, \mathrm{MgCl}_{2} 2$, and glucose 10. Equilibrium voltage across sEPSCs and sIPSCs recording solutions for $\mathrm{Cl}^{-}\left(\mathrm{E}_{\mathrm{Cl}}\right)$ and cation ions $\left(\mathrm{E}_{\text {cation }}\right)$ were $-51 \mathrm{mV}$ and $0 \mathrm{mV}$, respectively.

For recording $\mathrm{Na}^{+}$currents in HEK293 cells, cells were cotransfected with $\mathrm{Na}_{\mathrm{v}} 1.2^{\mathrm{WT}}, \mathrm{Na}_{\mathrm{v}} 1.2^{\Delta 1897}$, or $\mathrm{Na}_{\mathrm{v}} 1.2 \mathrm{Na}_{\mathrm{v}} 1.2^{1897-\text { STOP }}$ plasmid $(2 \mu \mathrm{g})$ with $\operatorname{Scn} 1 b(2 \mu \mathrm{g})$ and EGFP $(0.2 \mu \mathrm{g})$ and grown in $60 \mathrm{~mm}$ culture dishes for 48 hours before recording. $\mathrm{Na}^{+}$currents were elicited with a $50 \mathrm{~ms}$ depolarization step from $-100 \mathrm{mV}$ with $5 \mathrm{mV}$ increments at a holding potential of $-120 \mathrm{mV}$. Steady state inactivation was tested by a 2-pulse protocol with the first pulse of $500 \mathrm{~ms}$ from $-140 \mathrm{mV}$ to $-20 \mathrm{mV}$ at $5 \mathrm{mV}$ increments, followed by a second pulse fixed at $-20 \mathrm{mV}$. Gating activation curves were obtained using a Boltzmann function: $\mathrm{G} / \mathrm{G}_{\max }=(1+\exp [-(\mathrm{V}-$ $\left.\left.\mathrm{V}_{1 / 2} / / k\right]\right)^{-1}$, where $\mathrm{G} / \mathrm{G}_{\max }$ is the conductance normalized to its maximal value, $\mathrm{V}$ is the membrane potential, $\mathrm{V}_{1 / 2}$ is the membrane voltage at which the current amplitude is half-maximal, and $k$ is the slope factor. For steady state inactivation, $\mathrm{Na}^{+}$currents induced by the second pulse were normalized to the maximal current and plotted as the function of the voltages elicited by the first pulse, which was also fitted with Boltzmann function: $\mathrm{I} / \mathrm{I}_{\max }=\left(1+\exp \left[\left(\mathrm{V}-\mathrm{V}_{1 / 2}\right) / k\right]\right)^{-1}$, where $\mathrm{I} / \mathrm{I}_{\max }$ is the normalized value. Neuronal $\mathrm{Na}^{+}$currents were recorded in pyramidal and nonpyramidal shaped neurons in 5-7 DIV culture at the holding potential of -100 $\mathrm{mV}$. AP was elicited with $5 \mathrm{~ms}$ or $500 \mathrm{~ms}$ depolarization current in pyramidal shaped neurons from 6-9 DIV cultures, and the resting membrane potential was held around $-60 \mathrm{mV}$ with current injection.

Brain slices were placed in a recording chamber on the stage of an upright, infrared-differential interference contrast microscope (BX51WI, Olympus Optical) equipped with an ORCA-Flash2.8 C11440 Digital CMOS Camera (Hamamatsu Photonics), and they were continuously superfused at a rate of $2 \mathrm{~mL} / \mathrm{min}$ with aCSF bubbled with $95 \% \mathrm{O}_{2}$ and $5 \% \mathrm{CO}_{2}$ at $35^{\circ} \mathrm{C} \pm 0.04^{\circ} \mathrm{C}$. $\mathrm{mPFC}$ layer $5 / 6$ or BLA pyramidal neurons were visualized with a $40 \times$ water-immersion objective. sEPSCs were recorded at $-50 \mathrm{mV}$ (near $\mathrm{E}_{\mathrm{Cl}}$ ), and sIPSCs were obtained at $0 \mathrm{mV}$ (near $\mathrm{E}_{\text {cation }}$ ).

Recording pipettes were pulled from borosilicate glass with Sutter P-97 Micropipette Puller (Sutter Instrument Co). Pipette resistance ranged from 1.9 to $2.9 \mathrm{M} \Omega$ and 2.9 to $4 \mathrm{M} \Omega$; series resistance was $6.4 \pm 0.3 \mathrm{M} \Omega$ and $8.6 \pm 0.5 \mathrm{M}$, compensated by $80 \%$ and $60 \%-70 \%$ for $\mathrm{Na}^{+}$current recording in HEK cells and neurons, respectively. The pipette resistance ranged from 2.7 to $6.0 \mathrm{M} \Omega$ and series resistance was $11.1 \pm 0.3 \mathrm{M} \Omega$ without compensation for the recordings of postsynaptic currents in brain slices. In current patch-clamp experiments, input resistance was $222 \pm 12.7 \mathrm{M} \Omega$ for WT and $218 \pm 20.2 \mathrm{M} \Omega$ for $\operatorname{Scn} 2 a^{\Delta 1898 /+}$. Junction potential was measured immediately after recording by quickly detaching the pipette from the recorded cell. The measured junction potential was $2.2 \pm 0.3 \mathrm{mV}$ for WT and $1.4 \pm 0.2 \mathrm{mV}$ for $S c n 2 a^{\Delta 1898 /+}$, and data were not corrected.

Behavior analyses. Male and female heterozygous mice and their respective littermates (3-5 months old) were randomly assigned into experimental groups to perform locomotion, EPM, 3-chamber social interaction, and grooming behavioral tests. Specific protocols for these behavior tests were previously described (45). Male and female $S c n 2 a^{\Delta 1898 /+}$ mice were compared with their respective male and female WT littermate controls, and the investigator analyzing behaviors was blinded to the genotype. 
Locomotor activity measurement. The locomotor activity of WT and Scn $2 a^{\Delta 1898 /+}$ mice was measured in a 27.3 $\times 27.3 \mathrm{~cm}$ open-field locomotor activity chamber using open-field activity software (MED Associates). Distance traveled during the 1-hour test period was evaluated.

Grooming test. Grooming assay was performed in a dimly lit room ( 150 lux). Mice were allowed to habituate to the testing room for at least 30 minutes prior to the initiation of the assay. Each mouse was placed into a housing cage with low bedding, and its behaviors were recorded for 30 minutes. A new clean housing cage was used for each mouse. Grooming behavior was autoscored using pretrained autoscoring software validated previously (46).

Three-chamber social interaction test. The social test apparatus consisted of a box divided into 3 chambers of equal size $20 \mathrm{~cm}$ (length) $\times 40.5 \mathrm{~cm}$ (width) $\times 22 \mathrm{~cm}$ (height). A testing mouse was introduced to the middle chamber and left to habituate for 5 minutes, followed by another 5 -minutes, 3-chamber habituation by removing the retractable walls. After that, the mouse was briefly confined back to the middle chamber; then, an unfamiliar mouse (stranger) was introduced into a wire cage in one of the side chambers, and an object was introduced into a wire cage on the opposite side chamber. The testing mouse was allowed to freely explore all 3 chambers for 5 minutes after removing the retractable walls. All activities of the mouse in the chambers were recorded using AnyMaze software (Stoelting Co). Time spent in each chamber and time spent in the contact zone (1.5" radial diameter around the cup surrounding the wire cage containing the stranger mouse or object) were collected to evaluate sociability. The location of the stranger mouse and object were alternated between the 2 side chambers across the mice tested to avoid a side preference bias. Stranger mice (C57BL/6 male, 3 months old) were purchased from the Jackson Laboratory. Prior to behavioral testing, mice were habituated to the behavioral suite on each testing day.

EPM test. The EPM test was performed in an apparatus with 2 open arms and 2 closed arms. Two open arms $(25 \times 5 \times 0.5 \mathrm{~cm})$ across each other were perpendicular to 2 closed arms $(25 \times 5 \times 16 \mathrm{~cm})$ with a center platform $(5 \times 5 \times 0.5 \mathrm{~cm})$. The maze was elevated $40 \mathrm{~cm}$ above the floor. Experiments started by placing a mouse on the central platform facing an open arm. During the 5 minutes if free exploration, the number of entries into each arm, the time spent, and distance traveled in the arm were recorded using AnyMaze software (Stoelting Co.).

Stereotaxic viral delivery and fiber photometry. As previously described (47), the cohort of mice used for the EPM test in conjunction with fiber photometry recording were anesthetized with isoflurane, and $0.2 \mu \mathrm{L}$ pAAV1Syn-GCaMP6s-WPRE-SV40 (Addgene) was unilaterally injected into mPFC (AP: $+2.00 \mathrm{~mm}, \mathrm{ML}:-0.25 \mathrm{~mm}$, DV: $-2.25 \mathrm{~mm}$ ). During the same surgery, a $400 \mu \mathrm{m}$ diameter optical fiber (Doric) was implanted above the injection site in the $\mathrm{mPFC}$ (AP: $+2.00 \mathrm{~mm}, \mathrm{ML}:-0.25 \mathrm{~mm}, \mathrm{DV}:-2.15 \mathrm{~mm}$ ) and was secured with Metabond. Animals were tested 3 weeks after surgery.

Fiber photometry was performed to measure in vivo calcium dynamics during EPM. Mice were habituated to the patch cord $1 \mathrm{~min}$ in their home cage prior to behavioral testing. During the 5-minute test, a $470 \mathrm{~nm}$ LED excitation light (M470F3, Thorlabs) delivered at $521 \mathrm{~Hz}$ was passed through a filter (FF02-472/30, Semrock) and reflected by a dichroic glass (FF495-Di03, Semrock); it was coupled to the $0.48 \mathrm{NA}, 400 \mu \mathrm{m}$ core optical fiber patch cord (Doric) in order to excite GCAMP6s within neurons. Emitted fluorescence signals traveled back through the patch cord, passed through a dichroic filter (FF01-535/50, Semrock), and were captured by a photodetector (Model 2151, Newport). The modulated signal was demodulated and low-pass filtered using a corner frequency of $15 \mathrm{~Hz}$ through a RP2.1 real-time processor (Tucker Davis Technologies). A TTL pulse was sent to the processor at the start of each behavioral trial to allow the alignment of calcium signal recording to mouse behavior. Following behavioral testing, fluorescence microscopy was used to confirm GCAMP6s expression and optical fiber placement. Mice with improper placements were eliminated from the analyses.

Data were analyzed using a custom MATLAB script. Raw fluorescence signals were first detrended to account for any photobleaching by fitting a third-degree polynomial in 15-second time windows and subtracting this polynomial from the raw signal trace to calculate the change in florescence $(\Delta F / F)$. Next, the fluorescence signal was time locked to behavior as defined by entering the open or closed arm. Data were converted to a $Z$ score to account for variability in the dynamic range of the signal across animals and trials, and neural activity was quantified as the mean $Z$ score. To quantify the fluorescence level prior to arm entries during EPM, the mean $Z$ score was calculated over the 1 second prior to every arm entry as determined from behavioral data.

Simons VIP analysis. The Simons VIP v.3.0 data were queried for individuals who had an SCN2A variant and also had completed in-person clinical phenotyping. Autism diagnoses were confirmed with the ADOS (27). Caregivers completed the ADI-R, a standardized interview that is administered by a trained clinician with research reliability in administration and scoring (26). The ADI-R asks about current and past behaviors. Analyses focused on the social disinhibition item, and caregiver responses were coded into 4 categories (normal social 
disinhibition, occasional social disinhibition, definite social disinhibition, and marked social disinhibition). Data were analyzed from current behavior only.

Statistics. Numerical averages are presented as mean \pm SEM. Unless otherwise stated, statistical significance was calculated using the 2-tailed, unpaired $t$ tests; 1-way ANOVA; or 2-way ANOVA followed by a multiple-comparison test, based on the specific data set.

Study approval. The study was approved by Weill Cornell Medical College Animal Care and Welfare Committee (protocol no. 2016-0042). Animals were handled according to Guide for the Care and Use of Laboratory Animals (National Academies Press, 2011).

\section{Author contributions}

HGW, FSL, AMR, and GSP designed research studies; HGW, CCB, AL, and YB conducted experiments; HGW, CCB, AL, and YB acquired data; HGW, CCB, AL, JH, RMJ, YB, AMR, and GSP analyzed data; and HGW, AMR, and GSP wrote the manuscript.

\section{Acknowledgments}

This work was supported by NIH T32 DA039080 (CCB); the Leon Levy Foundation and a generous gift from the Mortimer D. Sackler Family Foundation (RMJ); NIH R01 NS052819 (FSL); NIH R01 DA029122, The Hartwell Foundation and the Weill Cornell Autism Research Program (AMR); and NIH R01 HL112918, R01 HL122967, R01 MH118934, Simons Foundation SFARI Explorer award no. 349984, and Holland-Trice Scholars Award (GSP). We thank Douglas Kim Laboratory at Janelia Research Campus of HHMI for sharing their pAAV1-Syn-GCaMP6s-WPRE-SV40 virus through Addgene.

Address correspondence to: Geoffrey S. Pitt, Weill Cornell Medicine, 413 East 69th Street, Belfer 502 / Box 190, New York, New York 10021, USA. Phone: 646.962.7641; Email: geoffrey.pitt@med.cornell.edu.

1. Yamagata T, et al. Nav1.2 is expressed in caudal ganglionic eminence-derived disinhibitory interneurons: mutually exclusive distributions of Nav1.1 and Nav1.2. Biochem Biophys Res Commun. 2017;491(4):1070-1076.

2. Boiko T, et al. Compact myelin dictates the differential targeting of two sodium channel isoforms in the same axon. Neuron. 2001;30(1):91-104.

3. Boiko T, et al. Functional specialization of the axon initial segment by isoform-specific sodium channel targeting. $J$ Neurosci. 2003;23(6):2306-2313.

4. Gatto CL, Broadie K. Genetic controls balancing excitatory and inhibitory synaptogenesis in neurodevelopmental disorder models. Front Synaptic Neurosci. 2010;2:4

5. O'Roak BJ, et al. Multiplex targeted sequencing identifies recurrently mutated genes in autism spectrum disorders. Science. 2012;338(6114):1619-1622.

6. Sanders SJ, et al. De novo mutations revealed by whole-exome sequencing are strongly associated with autism. Nature. 2012;485(7397):237-241.

7. Stessman HA, et al. Targeted sequencing identifies 91 neurodevelopmental-disorder risk genes with autism and developmentaldisability biases. Nat Genet. 2017;49(4):515-526.

8. Lim ET, et al. Rates, distribution and implications of postzygotic mosaic mutations in autism spectrum disorder. Nat Neurosci. 2017;20(9):1217-1224

9. Wolff M, et al. Genetic and phenotypic heterogeneity suggest therapeutic implications in SCN2A-related disorders. Brain. 2017;140(5):1316-1336.

10. Ben-Shalom R, et al. Opposing effects on NaV1.2 function underlie differences between SCN2A variants observed in individuals with autism spectrum disorder or infantile seizures. Biol Psychiatry. 2017;82(3):224-232.

11. Shin W, et al. Scn $2 a$ haploinsufficiency in mice suppresses hippocampal neuronal excitability, excitatory synaptic drive, and long-term potentiation, and spatial learning and memory. Front Mol Neurosci. 2019;12:145.

12. Spratt PWE, et al. The autism-associated gene Scn2a contributes to dendritic excitability and synaptic function in the prefrontal cortex. Neuron. 2019;103(4):673-685.

13. Middleton SJ, et al. Altered hippocampal replay is associated with memory impairment in mice heterozygous for the Scn2a gene. Nat Neurosci. 2018;21(7):996-1003.

14. Tatsukawa T, et al. Scn2a haploinsufficient mice display a spectrum of phenotypes affecting anxiety, sociability, memory flexibility and ampakine CX516 rescues their hyperactivity. Mol Autism. 2019;10(1):15.

15. Lena I, Mantegazza M. Na 1.2 haploinsufficiency in Scn2a knock-out mice causes an autistic-like phenotype attenuated with age. Sci Rep. 2019;9(1):12886.

16. Nelson SB, Valakh V. Excitatory/inhibitory balance and circuit homeostasis in autism spectrum disorders. Neuron. 2015;87(4):684-698.

17. Rubenstein JL, Merzenich MM. Model of autism: increased ratio of excitation/inhibition in key neural systems. Genes Brain Behav. 2003;2(5):255-267.

18. Yan H, et al. Calmodulin limits pathogenic Na+ channel persistent current. J Gen Physiol. 2017;149(2):277-293.

19. Gade AR, et al. An interaction between the III-IV linker and CTD in NaV1.5 confers regulation of inactivation by CaM and 
FHF. J Gen Physiol. 2020;152(2):e201912434.

20. Planells-Cases R, et al. Neuronal death and perinatal lethality in voltage-gated sodium channel alpha(II)-deficient mice. Biophys $J$. 2000;78(6):2878-2891.

21. Ogiwara I, et al. Nav1.2 haplodeficiency in excitatory neurons causes absence-like seizures in mice. Commun Biol. 2018;1(1):96.

22. Silverman JL, et al. Behavioural phenotyping assays for mouse models of autism. Nat Rev Neurosci. 2010;11(7):490-502.

23. Moy SS, et al. Sociability and preference for social novelty in five inbred strains: an approach to assess autistic-like behavior in mice. Genes Brain Behav. 2004;3(5):287-302.

24. Yang M, et al. Automated three-chambered social approach task for mice. Curr Protoc Neurosci. 2011;Chapter 8:Unit 8.26.

25. Sanders SJ, et al. Progress in Understanding and Treating SCN2A-Mediated Disorders. Trends Neurosci. 2018;41(7):442-456.

26. Rutter M, et al, eds. Autism Diagnostic Interview-Revised (ADI-R) Manual. Western Psychological Services; 2003.

27. Lord C, et al. The autism diagnostic observation schedule-generic: a standard measure of social and communication deficits associated with the spectrum of autism. J Autism Dev Disord. 2000;30(3):205-223.

28. Korenberg JR, et al. VI. Genome structure and cognitive map of Williams syndrome. J Cogn Neurosci. 2000;12(Suppl 1):89-107.

29. Sakurai T, et al. Haploinsufficiency of Gtf2i, a gene deleted in Williams Syndrome, leads to increases in social interactions. Autism Res. 2011;4(1):28-39.

30. Barak B, Feng G. Neurobiology of social behavior abnormalities in autism and Williams syndrome. Nat Neurosci. 2016;19(6):647-655.

31. Cryan JF, Holmes A. The ascent of mouse: advances in modelling human depression and anxiety. Nat Rev Drug Discov. 2005;4(9):775-790.

32. Vertes RP. Interactions among the medial prefrontal cortex, hippocampus and midline thalamus in emotional and cognitive processing in the rat. Neuroscience. 2006;142(1):1-20.

33. Duvarci S, Pare D. Amygdala microcircuits controlling learned fear. Neuron. 2014;82(5):966-980.

34. Bloodgood DW, et al. Fear extinction requires infralimbic cortex projections to the basolateral amygdala. Transl Psychiatry. 2018;8(1):60.

35. Luchkina NV, Bolshakov VY. Mechanisms of fear learning and extinction: synaptic plasticity-fear memory connection. Psychopharmacology (Berl). 2019;236(1):163-182.

36. Deneault E, et al. Complete disruption of autism-susceptibility genes by gene editing predominantly reduces functional connectivity of isogenic human neurons. Stem Cell Reports. 2018;11(5):1211-1225.

37. Feyder M, et al. Association of mouse Dlg4 (PSD-95) gene deletion and human DLG4 gene variation with phenotypes relevant to autism spectrum disorders and Williams' syndrome. Am J Psychiatry. 2010;167(12):1508-1517.

38. Chen R, et al. Deep brain optogenetics without intracranial surgery. Nat Biotechnol. 2021;39(2):161-164.

39. $\mathrm{Li} \mathrm{HH}$, et al. Induced chromosome deletions cause hypersociability and other features of Williams-Beuren syndrome in mice. EMBO Mol Med. 2009;1(1):50-65.

40. Segura-Puimedon M, et al. Heterozygous deletion of the Williams-Beuren syndrome critical interval in mice recapitulates most features of the human disorder. Hum Mol Genet. 2014;23(24):6481-6494.

41. Meyer-Lindenberg A, et al. Neural correlates of genetically abnormal social cognition in Williams syndrome. Nat Neurosci. 2005;8(8):991-993.

42. Cho JH, et al. Synaptic encoding of fear extinction in mPFC-amygdala circuits. Neuron. 2013;80(6):1491-1507.

43. Hubner C, et al. Ex vivo dissection of optogenetically activated $\mathrm{mPFC}$ and hippocampal inputs to neurons in the basolateral amygdala: implications for fear and emotional memory. Front Behav Neurosci. 2014;8:64.

44. Turrigiano G. Too many cooks? Intrinsic and synaptic homeostatic mechanisms in cortical circuit refinement. Annu Rev Neurosci. 2011;34:89-103.

45. Kabir ZD, et al. Rescue of impaired sociability and anxiety-like behavior in adult cacnalc-deficient mice by pharmacologically targeting eIF2 $\alpha$. Mol Psychiatry. 2017;22(8):1096-1109.

46. Jhuang H, et al. Automated home-cage behavioural phenotyping of mice. Nat Commun. 2010;1:68.

47. Bavley CC, et al. Cocaine- and stress-primed reinstatement of drug-associated memories elicit differential behavioral and frontostriatal circuit activity patterns via recruitment of L-type Ca(2+) channels. Mol Psychiatry. 2020;25(10):2373-2391. 